NBER WORKING PAPER SERIES

\title{
CROSS-GENERATIONAL DIFFERENCES IN EDUCATIONAL OUTCOMES IN THE SECOND GREAT WAVE OF IMMIGRATION
}

\author{
Umut Özek \\ David N. Figlio \\ Working Paper 22262 \\ http://www.nber.org/papers/w22262 \\ NATIONAL BUREAU OF ECONOMIC RESEARCH \\ 1050 Massachusetts Avenue \\ Cambridge, MA 02138 \\ May 2016
}

This research was supported by the National Center for the Analysis of Longitudinal Data in Education Research (CALDER) funded through Grant R305A060018 from the Institute of Education Sciences, U.S. Department of Education, and American Institutes for Research. We are grateful to Ran Abramitzky, Leah Boustan, Celeste Carruthers, Christina Felfe, Amy Schwartz, Steve Trejo, and seminar and conference participants and discussants at CESifo, AEFP, and APPAM for helpful comments and suggestions. We would also like to thank Florida Departments of Education and Health for providing the data used in this analysis. All opinions expressed in this paper are those of the authors and do not reflect the views of the Florida Departments of Education and Health or our funders. The views expressed herein are those of the authors and do not necessarily reflect the views of the National Bureau of Economic Research.

NBER working papers are circulated for discussion and comment purposes. They have not been peer-reviewed or been subject to the review by the NBER Board of Directors that accompanies official NBER publications.

(C) 2016 by Umut Özek and David N. Figlio. All rights reserved. Short sections of text, not to exceed two paragraphs, may be quoted without explicit permission provided that full credit, including $(\odot$ notice, is given to the source. 
Cross-Generational Differences in Educational Outcomes in the Second Great Wave of Immigration Umut Özek and David N. Figlio

NBER Working Paper No. 22262

May 2016

JEL No. I20,I24,J15

\begin{abstract}
We make use of a new data source - matched birth records and longitudinal student records in Florida - to study the degree to which student outcomes differ across successive immigrant generations. Specifically, we investigate whether first, second, and third generation Asian and Hispanic immigrants in Florida perform differently on reading and mathematics tests, and whether they are differentially likely to get into serious trouble in school, to be truant from school, to graduate from high school, or to be ready for college upon high school graduation. We find evidence suggesting that early-arriving first generation immigrants perform better than do second generation immigrants, and second generation immigrants perform better than third generation immigrants. Among first generation immigrants, the earlier the arrival, the better the students tend to perform. These patterns of findings hold for both Asian and Hispanic students, and suggest a general pattern of successively reduced achievement - beyond a transitional period for recent immigrants - in the generations following the generation that immigrated to the United States.
\end{abstract}

\author{
Umut Özek \\ American Institutes for Research/CALDER \\ 1000 Thomas Jefferson St. NW \\ Washington, DC 20007 \\ uozek@air.org \\ David N. Figlio \\ Institute for Policy Research \\ Northwestern University \\ 2040 Sheridan Road \\ Evanston, IL 60208 \\ and NBER \\ figlio@northwestern.edu
}




\section{CROSS-GENERATIONAL DIFFERENCES IN EDUCATIONAL OUTCOMES IN THE SECOND GREAT WAVE OF IMMIGRATION}

\section{Introduction}

Over the last five decades, the United States has experienced the second largest wave of immigration in its history. Triggered by the enactment of the Immigration and Nationality Act of 1965, this immigration flow gained further momentum in the 1990s and changed the demographic composition nationwide. The last thirty years have averaged more than one million documented immigrants per year, and unlike the earlier waves of immigration, the majority of these immigrants have come from Latin America and Asia. Immigrants and children of immigrants currently account for nearly a quarter of all school-aged children in the United States, and are projected to account for one-third by 2050 (Passel, 2011). How this new wave of immigrant youth fare in the U.S. public education system, therefore, has significant short-term and long-term welfare implications.

This paper presents the first use of matched administrative school and natality records to offer the most comprehensive analysis to date of the educational experiences of immigrants in the U.S. public school system. These remarkable data permit, for the first time, the study of educational outcomes across first, second, and third generation immigrants in the United States, and the exceptionally rich data we use from Florida administrative records provide the opportunity to follow hundreds of thousands of immigrant children longitudinally through school. In particular, we investigate the gaps in student achievement, misbehavior, truancy, persistence in high school, and college readiness upon graduation across immigrant generations, and explore how these gaps evolve across grades. We then examine the extent to which these gaps are driven by observable education production function inputs that are typically out of the 
control of school system such as socioeconomic differences, and potentially malleable factors such as differences in school quality.

There exists an extensive literature regarding the degree to which economic outcomes of immigrants converge to those of natives across generations; see Abramitzky and Boustan (forthcoming) for a review. Abramitzky, Boustan, and Erikkson (2014), studying the Age of Mass Migration, while finding evidence of partial convergence across generations, emphasize the importance of relative immigrant advantage or disadvantage over natives: The relative outcomes of second generation immigrants are strongly related to the relative position of the first generation from a sending country in comparison to natives. Borjas $(1994,1992)$ and Card, DiNardo, and Estes (2000), using multiple rounds of the Census, demonstrate strong degrees of intergenerational correlation in earnings.

What about the current wave of immigrants? Earnings gaps between immigrants and natives are greater now than they were in the Age of Mass Migration, and the ratio of development between the United States and today's major sending countries, such as China and Mexico, is considerably greater than the development gap between the United States and European sending countries in the Age of Mass Migration (Abramitzky and Boustan, forthcoming). At the same time, and counter to the negative/neutral selection observed in the Age of Mass Migration (Abramitzky and Boustan, forthcoming), there is evidence of positive selection among recent migrants to the United States from many sending countries (see, e.g., Jasso, et al., 2004; Feliciano, 2005; Kennedy et al., 2006; Grogger and Hanson, 2011), and in the case of Mexican immigrants, there is evidence of either negative selection (e.g, Ambrosini and Peri, 2012; Kaestner and Malamud, 2014) or that migrants are drawn from the middle of the skill distribution (e.g, Chiquiar and Hanson, 2005; Orrenius and Zavodny, 2005). There is clearly a 
tremendous amount to learn about the current wave of immigrants from historical data, but it is also valuable to supplement this knowledge with current measures of success.

There has been a fair amount of research on the educational attainment of immigrants compared to natives in the United States, but comparatively little is known about how well immigrant students perform while in school. ${ }^{1}$ This question is important for a number of reasons. For one, performance in school serves as an early indicator of later human capital formation and labor market outcomes, and studying school performance across different generations of immigrants at the present moment can provide evidence about the potential future success of children who are very recent immigrants to the United States. In addition, in an educational setting we can directly investigate the trajectories of improvement the longer children remain in the United States. These "intermediate" educational outcomes, which might help to explain some of the disparities in educational attainment and labor market outcomes, constitute the main focus of this study.

Two streams of research dominate the literature in this context, with most of the earlier studies relying on survey data (e.g. Kao and Tienda, 1995; Kao, 1999; Glick and White, 2003; Portes and MacLeod, 1996; Cortes, 2006; and White and Glick, 2009) whereas the more recent literature utilizes large administrative datasets (e.g. Schwartz and Stiefel, 2006; Conger et al., 2007; Stiefel et al., 2010). ${ }^{2}$ These papers tend to find evidence that immigrants outperform

\footnotetext{
${ }^{1}$ Some examples in the earlier sociological and anthropological literature are Carter and Segura (1979), Trueba (1987), Perlmann (1988), Ogbu (1978, 1987), and Ogbu and Matute-Bianchi (1986). See Chiswick and DebBurman (2004) for an overview of this literature. Several themes emerge from this literature. First, first generation immigrants tend to attain fewer years of schooling compared to natives. For instance, using Current Population Data (CPS), Chiswick and DebBurman (2004) show that first generation immigrants, on average, obtain two years less schooling compared to natives. Further, this schooling gap depends heavily on age at immigration, with immigrant adults who entered the U.S. early in childhood acquiring years of schooling comparable to native adults (Gonzalez (2003) and Chiswick and DebBurman (2004)). Also see Dustmann (2011) and Lüdemann and Schwerdt (2010) for a brief overview of the literature on the educational experiences of immigrants in European countries.

${ }^{2}$ A related strain of research examines the effect of immigrant students on their native peers. Recent examples in this context include Conger (2012); Cortes (2006); Schwartz and Stiefel (2009); and Gould, Lavy and Paserman
} 
native-born peers with the same ethnic identification, contradicting the notion of "straight-line assimilation" (Park, 1914; Gordon, 1964; Suarez-Orosco, 2000). ${ }^{3}$

That said, the literature has many unanswered questions that are relevant to current policy debates - most notably, how do first generation, second generation, and third generation immigrants perform relative to one another; how does this performance change as students age through school; and how much of these differences can be explained by different student, family, and school attributes? The lack of clarity on these questions is due to limitations in the existing data -- in particular, due to the inability to identify immigrant generation in school records. The administrative data and survey data employed in the existing literature each present different benefits and challenges in this context. For instance, using survey data to investigate "nativity gaps" allows comparisons between first, second, and third (and higher) generation immigrants as these data typically provide detailed information about the children's families (such as parental education and parents' countries of origin). However, most of these datasets contain a limited number of student outcomes (and no high-stakes outcomes), no information about the schools these students attend, and do not follow individual students over time. Further, studies that rely on survey data commonly suffer from small sample sizes, which hinder subgroup analysis and further complicate understanding potential mechanisms through which the relationships may be operating. On the other hand, large administrative datasets sometimes present very detailed information about student experiences in the public school system, yet they lack detailed information on family characteristics, and studies making use of administrative data are unable to

(2011). The overarching conclusion of these studies is that immigrant students have either small or no effect on the achievement levels of their native peers.

${ }^{3}$ In particular, immigrant students, especially those who migrate early in childhood, have been shown to perform comparable to or even better than their U.S.-born peers on elementary and middle school tests (Schwartz and Stiefel (2006), Kao (1999), Portes and MacLeod (1996), Kao and Tienda (1995), Cortes (2006)). 
identify second versus third generation immigrants ${ }^{4}$, and hence present comparisons between first generation immigrants and all other U.S. born students. Given that Duncan and Trejo (2016) demonstrate the degree to which self-identified ethnicity among second generation immigrants is selected (positive for Asian-Americans, and negative for Hispanic Americans), both types of datasets could lead to a very selected set of comparison students.

We make use of a unique dataset from Florida, in which student records are matched with birth certificate data for all children born between 1992 and 2002, in order to overcome the limitations of the prior literature and address a set of heretofore unanswered questions. Linking school records to birth records allows us to take advantage of the positive benefits of both administrative data and survey data in an environment in which we can observe outcomes for the entire population, and Florida is the only major immigrant-receiving state in the United States where it has proven feasible to match birth and school records to date. There are several distinct advantages that are realized as a consequence: First, the birth certificate data allow us to identify second generation immigrants, and offer the chance to observe a large range of variables (e.g., parental education and marital status) not observed in school records. They also enable us to contrast whether estimated cross-generational differences in educational outcomes are different depending on whether children are identified based on their stated ethnic identity or their parents' stated ethnic identity, permitting us to reduce the likelihood that our results are driven by the self-identification bias identified by Duncan and Trejo (2016). Moreover, because we can follow approximately two million individual students over more than a decade, including hundreds of thousands of foreign-born children and children of immigrants, we are able to examine the progress of immigrant students after they enter Florida public schools, and to

\footnotetext{
${ }^{4}$ We classify all children whose parents are U.S.-born as "third generation" immigrants. No population-level data source in the United States that is matchable to school records identifies grandparental birthplace.
} 
observe outcomes of first generation immigrants based on their timing of entry into the school system. Finally, using our administrative data, we can examine not only high-stakes outcomes like student test scores, high school graduation, and high school course-taking, but also noncognitive outcomes such as disciplinary incidents and truancy.

One limitation of using data from a single state is that the immigrants residing in that state may differ systematically from those living elsewhere in the country. We investigate this possibility directly using data from the American Community Survey, pooled across the years 2006-2014. We find that, indeed, Hispanic and Asian immigrants into Florida are positively selected (driven largely by the fact that Mexicans are relatively underrepresented in Florida versus the United States as a whole as a fraction of total immigrants). However, the degree of positive selection is not particularly great across generations: First generation Asian and Hispanic immigrants in Florida have 7.2 percentage point higher rates of maternal college education than their counterparts outside of Florida. ${ }^{5}$ For second generation immigrants in Florida, the difference is 5.7 percentage points, and for third-plus generation immigrants in Florida, the difference in 6.8 percentage points. ${ }^{6}$ Because of the apparent positive selection into Florida, driven largely by compositional differences, in the analysis that follows we stratify our analysis, to the extent possible, by country of origin to increase the external validity of our findings.

We find a general pattern of deteriorating educational outcomes across successive immigrant generations. In particular, we find that first generation immigrants - beyond a

\footnotetext{
${ }^{5}$ These figures are based on children aged five to sixteen, and make use of individual weights.

${ }^{6} \mathrm{We}$ can also compare second generation to third-plus generation immigrants born in Florida who remain versus leave the state and those born elsewhere in the United States who migrate to Florida versus those who do not. Second generation Florida stayers have lower levels of maternal education than second generation Florida leavers, in comparison with their third-plus generation counterparts, but the patterns are reversed regarding second versus thirdplus generation Florida in-migrants versus those who do not migrate to Florida.
} 
transition period - perform better in reading and math tests than do second generation immigrants, and second generation immigrants perform better than third generation immigrants. We also find that recent immigrants are significantly more likely to graduate from high school than more established generations, and are better prepared for college upon high school graduation. This pattern also holds true for student misbehavior and truancy, and for both Asian and Hispanic immigrants, and remain unchanged even after controlling for observed student, family and school attributes, or whether we use the student's or the mother's reported racial/ethnic identity.

These findings can be regarded as evidence against the straight-line assimilation theory if immigrant optimism indeed fades across successive generations. We find significant crossgenerational differences in the revealed educational preferences of Hispanic immigrants in elementary and high school, with second and third generation immigrants more likely to "undershoot" compared to observationally similar recent immigrants, presenting evidence of educational aspirations dissipating across generations.

These findings can also help to explain the patterns of racial and ethnic differences in educational trajectories as children progress through school. Clotfelter et al. (2009), for example, find that both Hispanic and Asian students gain on whites in reading and math tests as they progress between grades 3 and 8. We find that this relative gain in achievement among Hispanics is almost exclusively driven by first generation immigrants. On the other hand, both first and second generation Asian immigrants gain considerably on whites in reading and math tests between third and eighth grades.

\section{Data and Empirical Strategy}




\subsection{Data}

To address our research questions, we merge together two large data sets from the state of Florida: student-level administrative data and birth records. School records provide detailed information on all students in grades K-12 enrolled in Florida public schools between 2002-03 and 2011-12 school years, including performance on the high-stakes Florida Comprehensive Assessment Test (FCAT) in reading and math of all students between grades three and ten, courses taken in elementary, middle, and high school, student demographics, poverty, measures of English proficiency (limited English proficiency indicator and language spoken at home, as reported by parents), attendance, disciplinary incidents, and the country of birth for all students. This variable enables us to identify first generation immigrants in the population, as well as their countries of origin.

We merge these school records with the birth records of all children born in Florida between 1992 and 2002. The birth records identify maternal country of birth ${ }^{7}$, permitting us to differentiate between second generation immigrants and higher-order generations (which, for ease of explanation, we will call third generation immigrants). ${ }^{8}$ Birth records also record maternal self-reported ethnicity, allowing us to reduce the likelihood that our results are driven by bias associated with cross-generational differences in self-reported ethnicity discussed by

\footnotetext{
${ }^{7}$ During the time frame we examine in Florida, birth certificate applications listed the following options for the birth place of the mother: (1) United States; (2) Puerto Rico; (3) U.S. Virgin Islands; (4) Guam; (5) Canada; (6) Cuba; (7) Mexico; (8) Northern Marianas; (9) American Samoa; and (10) All others. While the application form provided additional space to write down the birth place if it is not listed, either very few applicants opted to specify, or very few were recorded. Therefore, we can credibly identify the birth place of the mother only for the countries listed above.

${ }^{8}$ Throughout the analysis, we identify second generation immigrants as those who were born in the U.S. to foreign born mothers. Another commonly used approach in this context is to define second generation as those who were born in the U.S. with at least one immigrant parent. In this study, we cannot utilize this alternative definition as we do not observe father's birthplace in the birth records. Therefore, it is important to note that some students who would be identified as second generation under the alternative are categorized as third generation in our analysis. However, this should not be a great concern, since, based on the recent Census estimates, among the households with a native wife, only 3 percent have a foreign-born husband in the U.S. (http://www.census.gov/prod/2013pubs/acsbr11-16.pdf, accessed 4/18/2014).
} 
Duncan and Trejo (2016). Furthermore, the birth records offer background information not typically seen in school records including maternal education and marital status. Because the birth-school match is based on full name, exact date of birth, and social security numbers, the birth and school records are virtually perfectly matched (Figlio et al., 2014). ${ }^{9} \mathrm{~A}$ high match rate is especially important when considering a Hispanic population, given the higher concentration of Hispanic surnames relative to names from other origins, as well as the uneven treatment of Hispanic mothers' and fathers' family names in children's administrative records. Because we can determine second versus third generation immigrant status only for Florida-born children born between 1992 and 2002, we restrict the data for non-Florida-born children to those years of birth as well.

Florida is an ideal location in this context both because of its outstanding student longitudinal data system and also because of its position as one of the major destinations for the recent wave of immigration. Currently, foreign born individuals constitute one-fifth of the population in Florida, and 9.2 percent of all foreign-born individuals and 8.5 percent of all foreign-born children in the United States reside in Florida. Further, the composition of these immigrants closely resemble the new wave of immigrants nationwide: 85 percent of the current immigrant population in Florida was born in Latin America or Asia. In the 2009-10 school year, one-tenth of all Florida K-12 public school students were born outside of the U.S, and another quarter of Florida's students had foreign-born parents. Therefore, Florida can be regarded as a mirror for the future demographics of the public school system in the United States.

Figure 1 presents the distribution of immigrant generations by major race/ethnicities in Florida. In this graph, the first category represents the foreign born students, the second category

\footnotetext{
${ }^{9}$ As Figlio et al. (2014) demonstrate, the match rate is essentially identical to that which would have been predicted based on the American Community Survey data.
} 
identifies students born in Florida to foreign born mothers, the third category represents Florida born students with U.S. born mothers, and the fourth category denotes students born in another state in the U.S. Overall, 71 percent of children in Florida public schools were born either outside of the U.S. or in Florida - a necessary condition for understanding second versus third generation immigrant status. Of those for whom it is possible to divine immigrant generation, about 14 percent are first generation immigrants, 21 percent are second generation, and 66 percent are third generation (or longer ago) immigrants. The distribution among Hispanic and Asian students, on the other hand, reflect the recent wave of immigration into the U.S., with the majority of Hispanic and Asian students being first or second generation immigrants. For instance, among Hispanics born either in Florida or abroad, 33 percent of the students are foreign born and 47 percent have an immigrant mother. Among Asians born either in Florida or abroad, 43 percent of the students are foreign born and 54 percent have an immigrant mother. One-fifth of Hispanics and three percent of Asians for whom we can determine generation status are in the third or higher generation. In our main analysis, we exclude the students born in another state as we cannot identify their immigrant generation. ${ }^{10}$

Table 1 presents the distribution of country of birth among first generation Hispanic and Asian immigrants, and portrays the diversity of the immigrant population in Florida. For instance, over 90 percent of the first generation Hispanic immigrants in the sample were born in 14 countries, with the majority coming from Cuba (22 percent), Mexico (17 percent), Colombia (12 percent), and Puerto Rico (10 percent). In any analysis of Hispanic immigrants in Florida, especially in a location such as Florida, there is the question of how to characterize those who were born (or whose parents were born) in Puerto Rico and Cuba. 10 percent (23 percent) of first

\footnotetext{
${ }^{10}$ To check the robustness of our findings to this restriction, we compare the nativity gaps in eighth grade test scores using all U.S. born students in our sample and the nativity gaps obtained using only Florida-born second and higher generation students in the online appendix, and show that patterns remain unchanged.
} 
generation Hispanic immigrants and 11 percent (20 percent) of second generation Hispanic immigrants in Florida are of Puerto Rican (Cuban) origin, so this is a meaningful decision in the present analysis. Immigrants from both countries tend to be more advantaged socioeconomically and contextually/linguistically than other Latino groups (Galindo and Reardon, 2006) and have consistently outperformed Hispanic immigrants from other countries (ACT, 2007), and, of course, all Puerto Ricans are themselves U.S. citizens, so their status as "immigrants" in the U.S. is somewhat different from immigrants from other places besides Puerto Rico. In our main analysis, we include first and second generation Puerto Rican and Cuban immigrants. That said, all of our results reported below are virtually unchanged when we exclude these students from the analysis. ${ }^{11}$

\subsection{Empirical Framework}

We are interested in five distinct student outcomes: (1) FCAT scores in reading and math standardized to zero mean and unit variance at the grade-year level; (2) disciplinary problems (as measured by whether the student was involved in a disciplinary incident); (3) attendance (percent absent days); (4) on-time high school graduation (whether the student received a standard high school diploma within four years after entering the ninth grade for the first time); and (5) college readiness as measured by whether the student took a college credit-bearing course ${ }^{12}$ before high school graduation. Along these five dimensions, we compare first, second and third generation Hispanic and Asian immigrants, with third generation white students - that is, white students

\footnotetext{
${ }^{11}$ Results of analyses in which we exclude first and second generation Puerto Rican and Cuban immigrants are available in the online appendix.

${ }^{12}$ Florida offers a wide array of high school acceleration programs for students to earn college credit while in high school, including Advanced Placement (AP), International Baccalaureate (IB), Advanced International Certificate of Education (AICE), and dual enrollment (DE) courses. In our main analysis, we focus on AP, IB, and AICE coursetaking in math, science, English, and social studies because these courses are offered in the K-12 system and hence included in our data.
} 
whose mothers were born in the United States -- as the baseline group. In the case of student test scores, disciplinary incidents, and attendance, we measure these outcomes in the eighth grade so that it is more reasonable to assume that the estimated differences between early entering first generation and later generations can be interpreted as relatively permanent. This restriction leaves us with seven birth cohorts of students who are old enough to reach the eighth grade by the end of our sampling frame (students born between 1992 and 1998). For the high school outcomes, we are limited to those students born between 1992 and 1994, because of the years of data availability.

We execute our analysis by dividing individuals into eleven groups - first generation immigrants who first arrive in the school system in each grade from eighth (latest-arriving immigrants) to kindergarten (earliest-arriving immigrants) ${ }^{13}$; second generation immigrants whose mothers were born outside of the United States; and third generation "immigrants" whose mothers were born in the United States but who identify as having either an Asian identity or a Hispanic identity. Because of the possibility of bias in self-identification of Asians and Hispanics described by Duncan and Trejo (2016), we identify the set of second and third generation immigrants based either on child's ethnic identification in school or mother's ethnic identification at the time of the child's birth.

We present three basic sets of analyses. In the first set of models, we show raw comparisons across the generations, and for first generation students, across age at entry, controlling only for disability status, age at $8^{\text {th }}$ grade, year, and gender. In the second set of models, we include a set of control variables: Because immigrants might attend systematically

\footnotetext{
${ }^{13}$ To identify students who enter the school system as early as KG, we restrict the sample to students born in 1997 and 1998 for whom it is possible to track students all the way from KG to the $8^{\text {th }}$ grade in our sampling frame. In other analysis, we divide the first generation immigrants into two groups - immigrants who enter the Florida public school system by the third grade (early entering) and those who enter after the third grade (late entering). In the latter analysis, we use all students born between 1992 and 1998 and subsequently attended a Florida public school.
} 
different sets of schools depending on generation, we control for school by cohort fixed effects ${ }^{14}$ so that we are directly comparing immigrants from different generations attending the same schools. In addition, we control for a measure of low-income status (free or reduced-price lunch eligibility) and language minority status ${ }^{15}$ (whether or not English is spoken at home). ${ }^{16}$ In the third set of models, we further control for a set of family background characteristics observed on the birth certificate - maternal education and marital status. Our objective in presenting these multiple sets of models is to show the degree to which cross-generational differences, and differences across first generation students depending on age at entry, are sensitive to whether or not we control for variables that can be correlated with immigrant generation or perhaps age at entry. We cluster all standard errors at the school-by-year level.

In addition to studying cross-generational differences in eighth grade levels of outcomes, we also follow individual students over time, and examine how these gaps evolve between third and eighth grades using early entering first, second and third generation immigrants.

\section{Results}

Tables 2 and 3 present the descriptive statistics for our five outcomes of interest and student/family attributes, comparing third generation white students with Hispanic students by

\footnotetext{
${ }^{14}$ For test scores, disciplinary incidents and attendance, we use the year the student enters the eighth grade for the first time, and the school attended during that year to define cohorts. For high school graduation, we use the year the student enters the ninth grade for the first time, and the high school attended during that year.

${ }^{15}$ Several studies in the literature use limited English proficiency (LEP) as a covariate in this context (e.g. Schwartz and Stiefel (2006), and Kao and Tienda (1995)). We choose not to follow this approach for the following reason. In Florida, an LEP student is defined as "a student whose home language is one other than English and whose English aural comprehension, speaking, reading, or writing proficiency is below the average English proficiency level of English speaking". Therefore, once native language is controlled for, LEP status captures the differences between the language skills of students, which are likely correlated with differences in their cognitive development.

Therefore, regressions controlling for the LEP status might understate the underlying cognitive differences across immigrant generations. Because we have information about home language itself, we believe that it is preferable to control for home language - which we consider an input into the education production process - rather than LEP status - which we consider a potential outcome.

${ }^{16}$ We also show in Appendix A what happens as we control successively for each set of these control variables.
} 
generation in Table 2, and third generation white students with Asian students by generation in Table 3. For ease of tabular comparison, we present descriptive statistics just for early entering (those who entered the public school system by the third grade) versus late entering first generation students. These raw statistics reveal that outcomes differ, sometimes dramatically, across generations, yet the same general pattern is observed for both Asian and Hispanic immigrants with worsening educational outcomes as we move from recent immigrants to more established immigrant generations beyond a transitional period for first generation immigrants. For instance, foreign-born Hispanic students who enter the school system after the third grade score roughly 90 percent of a standard deviation worse in eighth grade reading tests (roughly $0.6 \sigma$ worse in math) than third generation white students, are 16 percentage points (30 percent) less likely to graduate from high school, and are 13 percentage points (25 percent) less likely to take a college credit-bearing course before graduating from high school. In stark contrast, the Hispanic gap in test scores shrinks to about $0.2 \sigma$ in reading and math for early entering first generation Hispanics, and goes up to $0.28 \sigma$ for second generation Hispanics, and further increases to about $0.3 \sigma$ for third generation (or higher) Hispanics. Similarly, recent Hispanic immigrants (early entering first and second generation) have more favorable disciplinary outcomes and attendance records, are significantly more likely to graduate from high school, and are more likely to take an AP, IB, or AICE course before graduating from high school than third generation immigrants. The same patterns are observed for Asians, with more favorable outcomes than third generation whites along all five dimensions.

Interestingly, the findings reported in these two tables also reveal that recent immigrants outperform more established generations despite the evidence that immigrants accumulate wealth and education across generations, and that later generations have significantly better English 
skills than recent immigrants. For instance, among Hispanics, 75 percent of early entering first generation immigrants are eligible for subsidized meals, compared to 70 percent among second generation Hispanics, and 59 percent among third generation. Similarly, one-third of second generation Hispanic immigrants have mothers with less than a high school degree, compared to 30 percent for third generation. 84 percent of the early entering first generation Hispanics have been categorized as limited English proficient at least once since they entered the public school system, in stark contrast to 60 percent for second generation, and 27 percent for third generation Hispanics. Similar, yet considerably smaller, cross-generational differences in wealth, education and English skills are observed among Asian immigrants.

\subsection{Cross-generational Differences in Educational Outcomes}

Figure 2 illustrates the patterns of eighth grade reading and math test scores for Hispanic and Asian students, arrayed from left to right in terms of the amount of time spent in the United States. It's clear that whether or not we present raw differences or differences controlling for school fixed effects and background characteristics, the patterns of results are the same: For both Asian and Hispanic students, the latest arriving first generation students fare the worst, and eighth grade test scores rise essentially monotonically with the amount of time spent in the United States, peaking for those who began kindergarten in Florida schools. Second generation students, either Asian or Hispanic, perform worse than the earliest-arriving first generation students, and third generation students tend to perform worse still. For Asians, there is essentially no difference between the models in which we control for school fixed effects and background characteristics and those in which we control for just disability, year, age, and gender. For Hispanics, it makes a difference regarding level of performance whether or not we control for 
these variables - across the board, Hispanic students are estimated to perform relatively better (and for the earliest-arriving first generation immigrants, exceed third generation white performance) in models where we control for a variety of factors than in cases in which we don't control for these variables. But the control variables simply shift the relationship relative to third generation white students; they do not alter the relationship across generations for Hispanic students virtually at all.

As discussed by Duncan and Trejo (2016), this pattern of declining test scores across successive immigrant generations might be indicative of bias associated with cross-generational differences in self-reported ethnicity. To investigate this possibility, we replicate the analysis in Figure 2 using the maternal racial identity reported in birth records to identify race/ethnicity for second and third generation immigrants, using third generation white students with non-Hispanic and non-Asian mothers as the baseline group. If the decline in test scores is indeed driven by negative selection into later generations, one would expect the achievement gaps between early entering first generation immigrants and more established generations to decrease when Hispanic and Asian identity is defined based on mothers' self-reported race/ethnicity. ${ }^{17}$

Figure 3 presents the cross-generational differences obtained using our baseline model where the first set of estimates (labeled "Student Hispanic" and "Student Asian") use the selfreported race/ethnicity of the student, whereas the second set of estimates (labeled "Mother Hispanic" and "Mother Asian") use the self-reported race/ethnicity of the mother to identify Hispanic and Asian second and third generation immigrants. In both cases, first generation

\footnotetext{
${ }^{17}$ With regard to Hispanic immigrants, changes between maternal ethnic identity and children's ethnic identity are the same across generations: Among children of mothers who self-identify as Hispanic, 73 percent of second generation immigrants identify as Hispanic and 74 percent of third generation immigrants identify as Hispanic. But there are large cross-generational differences with regard to Asians. Among children of mothers who self-identify as Asian, 70 percent of second generation immigrants identify as Asian but only 34 percent of third generation immigrants identify as Asian. This suggests that Asian immigrants have integrated across generations in a different manner than have Hispanic immigrants.
} 
immigrants are classified based on their self-reported racial/ethnic identity, and third generation white students are used as the baseline group. Among both Hispanics and Asians, we find that the general patterns in the cross-generational differences in test scores remain unchanged whether we use the student's or the mother's self-reported racial/ethnic identity to classify second and third generation Hispanics or Asians. In the online appendix (Figures 4-6), we repeat the same analysis for Hispanics excluding students of Cuban or Puerto Rican origin, and show that the conclusions remain unchanged. To investigate whether changes in the national origin composition of Hispanics and Asians across generations account for any of the observed crossgenerational differences, we break down the Hispanic and Asian analyses for first and second generation by country of origin (Puerto Ricans, Cubans, Mexicans, and all others for Hispanics; Filipinos, Chinese, Japanese, and all others for Asians ${ }^{18}$ in Appendix Figures B1-B4, and show that second generation immigrants perform either worse than, or comparable to early-entering first generation immigrants.

In Appendix Table A1 we present the results in which we move from the first to the second model sequentially, first controlling for school by cohort fixed effects, then controlling for native language spoken, then controlling for low-income status, and then finally controlling for maternal background factors. Two findings are worth highlighting when making the step-bystep controls. First, the observed differences in English language skills, wealth and education between Hispanics and third generation whites explain a significant portion of the Hispanic achievement gaps (except for the late-entering first generation immigrants), yet the extent of their role in explaining these gaps diminish across generations. Second, the acquisition of English language, wealth and education across immigrant generations explain very little of the

\footnotetext{
${ }^{18} \mathrm{We}$ are limited to these countries of origin because Puerto Ricans, Cubans, and Mexicans are the only Hispanic groups independently identified on the birth certificate under maternal place of birth, while Chinese, Japanese, and Filipinos are the only Asian groups identified on the birth certificate under maternal race.
} 
cross-generational differences in educational outcomes among Hispanics and Asians. Table 1 in the online appendix presents the same set of analyses in models excluding Cuban and Puerto Rican students, and demonstrates that the patterns remain the same regardless of our treatment of these student groups.

We next turn to attendance and behavioral outcomes, as reported in Figure 4 (and Appendix Table A2, and Table 2 in the online appendix for specifications excluding Cuban and Puerto Rican students). Again, with these outcomes the differences across generations (as well as when compared with third generation white students) are very similar whether or not we control for a variety of background factors and school-by-cohort fixed effects. For the most part, there is not much of a pattern in disciplinary incidents and absenteeism across timing of first generation entry, and second generation Asian and Hispanic students have disciplinary and absenteeism outcomes similar to first generation students. For third generation students, however, outcomes tend to be worse for both Hispanic and Asian students - with often markedly increased rates of both disciplinary outcomes and absenteeism relative to first and second generation immigrants. Third generation Hispanic absenteeism rates are very similar to third generation white absenteeism rates (and third generation Hispanic disciplinary rates exceed third generation white rates), while third generation Asian disciplinary rates are very similar to third generation white disciplinary rates.

Patterns like those seen regarding test scores re-emerge when considering on-time high school completion and advanced course-taking in high school, as presented in Figure 5 (and Appendix Table A3, and Table 3 in the online appendix for specifications excluding Cuban and Puerto Rican students). Because of data limitations, for these outcomes we cannot differentiate amongst the earliest entrants - all we know is whether a student arrived in third grade or earlier. 
Nonetheless, the same inverse-U shaped pattern emerges for both Hispanic and Asian immigrants across generations and within the first generation. Among first generation students, the probability of on-time graduation and the likelihood of taking advanced high school classes increase the earlier the student arrived in Florida public schools. Second generation students fare similarly to the earliest arriving first generation students, and then third generation students fare worse than second generation students. As with the pattern seen with test scores, it appears that higher-generation Hispanic and Asian students begin to fall back relative to their early-entering first generation peers. We also inspect the possible role of selection into later generations along these two outcomes (not reported here), and find that these patterns persist whether we use students' or mothers' racial/ethnic identify to classify second and third generation Asian and Hispanic immigrants.

\subsection{Cross-Generational Differences in Student Progress}

Beyond cross-sectional comparisons in educational outcomes across immigrant generations, we also examine how these gaps in student outcomes evolve across grades. For this exercise, we construct a balanced panel of students who are observed in each grade from three through eight, and compare (regression-adjusted) patterns of test score growth across grades for first, second, and third generation Hispanic and Asian students, relative to third generation white peers. ${ }^{19}$ For this analysis, it is of course necessary that we concentrate only on early-entering first generation immigrants, as we need to observe third grade test scores for them.

Figure 6 presents these over-time patterns for the same students. (Similar patterns can be observed in the raw data, and are presented in the online appendix, Figures 2 and 3.) As can be seen, second and third generation Hispanic students tend to maintain their same position relative

\footnotetext{
${ }^{19}$ Note that since this specification involves controlling for school-by-cohort fixed effects, we are comparing students to their peers at the same schools.
} 
to third generation white students in both reading and math over the grades considered, while first generation Hispanic students make rapid progress across the grades, eventually overtaking second and third generation Hispanics (and, in the case of reading, third generation whites as well, in the regression-adjusted specification). Third generation Asians maintain their position relative to third generation white students, while both first and second generation Asian students improve in relative terms over the six-grade period, with first generation students eventually pulling away from second generation students as well. These patterns suggest that Clotfelter et al.'s (2009) findings that Asian and Hispanic students' test scores in North Carolina grow more rapidly across the grades than do white students' scores are driven by first and (in the case of Asian students, second) generation immigrants, and likely not by the more generationallyestablished Asian and Hispanic-identifying families.

We perform the same analysis looking at disciplinary incidents and truancy across the same grades; these results are presented in Figure 7. In the case of disciplinary incidents, all Hispanic students tend to have similar or lower rates of disciplinary incidents to third generation white students in the elementary grades, a relationship that holds in the middle grades for first and second generation Hispanic students. Third generation Hispanic students, on the other hand, have more disciplinary incidents in the middle school grades. For Asian students, all generations have fewer disciplinary incidents in the elementary school grades, but in the middle grades the third generation Asian students' disciplinary issues are indistinguishable from those of third generation whites, while first and second generation Asian students have substantially fewer disciplinary incidents in the middle school grades. Regarding absences, the relative patterns across the generations appear to be highly stable across grades for both Asian and Hispanic 
students. We repeat the same analysis excluding students of Cuban or Puerto Rican origin (reported in Figure 7 in the online appendix), and find similar patterns.

\subsection{Other Possible Mechanisms behind the Cross-Generational Gaps}

So far, beyond a transition period for first generation immigrants after their initial entry into the school system, our findings have shown a steady decline in student performance across generations even after controlling for observed student, family and school traits, with earlyarriving first generation immigrants academically outperforming those born in the United States, and those born in the United States to foreign-born mothers tending to academically outperform those born in the United States to native-born mothers. That said, there is not a clear-cut pattern regarding truancy and disciplinary outcomes - just regarding test scores, high school completion, and high school course-taking.

Aside from the aforementioned negative racial/ethnic selection into later generations, the decline in academic outcomes across successive immigrant generations might be interpreted as evidence against the straight-line assimilation theory if immigrant optimism fade across generations, with more established generations passing their leveled aspirations to their children. This decline in educational motivation might manifest itself in cross-generational differences in revealed educational preferences among observationally equivalent students. We investigate this possibility in the context of school choice behavior in middle school and advanced course-taking behavior in high school. For the former exercise, we focus on students in the last year of elementary school and examine whether first generation immigrants are more likely to choose a high-performing middle school (schools that received a grade of 'A' or 'B' in Florida's school accountability system) in the following year, compared to their second and third generation peers in the same elementary school with similar achievement levels and socioeconomic status. In the 
latter exercise, we once again estimate the cross-generational gaps in college credit-bearing course-taking among high school graduates, yet, this time, we also account for the differences in eighth grade test scores. In both cases, we exclude late-entering first generation immigrants from the analysis, and use early-entering first generation immigrants as the baseline group.

We find significant differences in the educational choices of first, second, and third generation Hispanic students, with second and third generation Hispanics more likely to "undershoot" compared to their foreign-born Hispanic peers. In particular, the estimates presented in the first two columns of Table 4 reveal that first generation Hispanics are 4 percentage points (about 8 percent) more likely to choose a high-performing middle school, and 3 percentage points more (about 6 percent) more likely to take advanced high school courses compared to their observationally similar second generation peers, who are, in turn, less likely to undershoot compared to their third generation Hispanic peers (even though the gap shrinks considerably when we control for maternal attributes). We find similar, yet less precise, crossgenerational differences among Asian immigrants (reported in the third and fourth columns of Table 4).

\section{Conclusion}

This paper presents the first comprehensive look at the relative performance of early arriving first generation immigrants, late-arriving first generation immigrants, second generation immigrants, and third generation immigrants using population-level data in the United States. A clear pattern of results emerges, at least for the Florida public school students identified as Asian or Hispanic whom we study: We observe that while first generation immigrants who arrive in Florida in fourth grade or later consistently perform at a level that is lower than other students, first generation students who arrive in Florida in third grade or earlier generally perform better 
than any other generation of students who share their same ethnicity. Second generation Asian and Hispanic students in turn tend to perform better than do third generation students of the same ethnicity.

These results have potential implications for immigration policy and how one perceives the role immigrants play in American schools and beyond. They suggest that while it appears that newly-arrived immigrant children perform very poorly and require considerable resources, not only do these children catch up very quickly to their native-born co-ethnic peers, but for those who arrived before the age of nine or so, they tend to exceed the performance of their native-born co-ethnic peers. And the U.S.-born children of foreign-born individuals, regardless of when they arrived in the United States, tend to outperform others from the same ethnicity whose families have lived longer in the country. While understanding the cultural and economic mechanisms behind these patterns of findings is beyond the scope of the present project, it will be important to understand why, for instance, third generation Asian students no longer possess the relative academic advantages of first and second generation Asian students, and why third generation Hispanic students appear to fall back academically relative to their first and second generation Hispanic peers. 


\section{References}

Abramitzky, Ran and Leah Platt Boustan (forthcoming). Immigration in American Economic History. Journal of Economic Literature.

Abramitzky, Ran, Leah Platt Boustan, and Katherine Eriksson (2014). A Nation of Immigrants: Assimilation and Economic Outcomes in the Age of Mass Migration. Journal of Political Economy 122 (3): 467-506.

Abramitzky, Ran, Leah Platt Boustan, and Katherine Eriksson (2012). Europe's Tired, Poor, Huddles Masses: Self-Selection and Economic Outcomes in the Age of Mass Migration. American Economic Review 102 (5), 1832-56.

ACT. (2007). State of College Readiness for Latino Students. Iowa City, IA: ACT.

Akbulut-Yuksel, Mevlude and Adriana Kugler (2016). Intergenerational Persistence of Health in the U.S.: Do Immigrants Get Healthier as they Assimilate? NBER working paper 21987.

Ambrosini, J. William and Giovanni Peri (2012). The Determinants and the Selection of MexicoUS Migrants. The World Economy 35 (2): 111-51.

Borjas, George J. (2014). The Slowdown in the Economic Assimilation of Immigrants: Aging and Cohort Effects Revisited Again. NBER Working Paper 19116.

Borjas, George J. (1994). Long-Run Convergence of Ethnic Skill Differentials: The Children and Grandchildren of the Great Migration. Industrial and Labor Relations Review 47 (4): 553-73.

Borjas, George J. (1992). Ethnic Capital and Intergenerational Mobility. Quarterly Journal of Economics 107 (1): 123-50.

Card, David, John DiNardo, and Eugena Estes (2000). The More Things Change: Immigrants and the Children of Immigrants in the 1940s, the 1970s, and the 1990s. In Issues in the Economics of Immigration, edited by George J. Borjas. 227-70. Chicago: University of Chicago Press.

Carter, Thomas P. and Roberto D. Segura (1979). Mexican Americans in School: A Decade of Change. New York: College Entrance Examination Board.

Chiquiar, Daniel and Gordon Hanson (2005). International Migration, Self-Selection, and the Distribution of Wages: Evidence from Mexico and the United States. Journal of Political Economy 113 (2): 239-81.

Chiswick, Barry R., and Noyna DebBurman (2004). Educational attainment: analysis by immigrant generation. Economics of Education Review 23, 361-379. 
Clotfelter, Charles T., Helen F. Ladd, and Jacob L. Vigdor (2009). The Academic Achievement Gap in Grades 3 to 8." Review of Economics and Statistics 91 (2): 398 - 419.

Conger, Dylan (2012). Immigrant Peers and Academic Performance in High School. George Washington University Working Paper.

Conger, Dylan, Amy E. Schwartz and Leanna Stiefel (2007). Immigrant and Native-born Differences in School Stability and Special Education: Evidence from New York City. International Migration Review 41(2), 402-431.

Cortes, Kalena E. (2006). The effects of age of arrival and enclave schools on the academic performance of immigrant children. Economics of Education Review $25,121-132$.

Duncan, Brian and Stephen Trejo (2016). The Complexity of Immigrant Generations: Implications for Assessing the Socioeconomic Integration of Hispanics and Asians. NBER working paper 21982.

Dustmann, Christian, Tomasso Frattini and Gianandrea Lanzara (2011). Educational Achievement of Second Generation Immigrants: An International Comparison. NORFACE MIGRATION Discussion Paper No. 25.

Feliciano, Cynthia (2005). Educational Selectivity in US Immigration: How Do Immigrants Compare to Those Left Behind? Demography 42 (1): 131-52.

Figlio, David, Jonathan Guryan, Krzysztof Karbownik, and Jeffrey Roth (2014). The Effect of Poor Neonatal Health on Children's Cognitive Development. American Economic Review.

Galindo, C., and Reardon, S. F. (2006). Latino students' educational experiences and opportunities during kindergarten. Tempe, AZ: National Task Force on Early Childhood Education for Hispanics.

Glick, Jennifer E., Michael J. White (2003). The academic trajectories of immigrant youths: analysis within and across cohorts. Demography 40 (4), 759-783.

Gonzalez, Arturo (2003). The education and wages of immigrant children: the impact of age at arrival. Economics of Education Review 22, 203-212.

Gordon, Milton M. (1964). Assimilation in American Life: The Role of Race, Religion, and National Origins. New York: Oxford University Press.

Gould, Eric D., Victor Lavy and M. Daniele Paserman (2011). Sixty Years after the Magic Carpet Ride: The Long-Run Effect of the Early Childhood Environment on Social and Economic Outcomes. Review of Economic Studies, 78(3), 938-973. 
Grogger, Jeffrey and Gordon Hanson (2011). Income Maximization and the Selection and Sorting of International Migrants. Journal of Development Economics 95 (1): $42-57$.

Jasso, Guillermina, Douglas Massey, Mark Rosenzweig, and James Smith (2004). Immigrant Health: Selectivity and Acculturation. Critical Perspectives on Racial and Ethnic Differences in Health in Late Life: 227-66.

Kaestner, Robert and Ofer Malamud (2014). Self-Selection and International Migration: New Evidence from Mexico. Review of Economics and Statistics 96 (1): 78-91.

Kao, Grace (1999). Psychological well-being and educational achievement among immigrant youth. In Children of immigrants: Health, adjustment, and public assistance, edited by D. J. Hernandez. Washington, DC: National Academy Press, 410-77.

Kao, Grace and Marta Tienda (1995). Optimism and achievement: the educational performance of immigrant youth. Social Science Quarterly 76, 1-19.

Kennedy, Steven, James Ted McDonald, and Nicholas Biddle (2006). The Healthy Immigrant Effects and Immigrant Selection: Evidence from Four Countries. Social and Economic Dimensions of an Aging Population Research Paper 164.

Lüdemann, Elke and Guido Schwerdt (2010). Migration Background and Educational Tracking: Is there a Double Disadvantage for Second-Generation Immigrants?. CESifo Working Paper Series 3256, CESifo Group Munich.

Ogbu, John U. (1987). Variability in Minority School performance: A Problem in Search of an Explanation. Anthropology and Education Quarterly. 18 (4); 313334.

Ogbu, John U. and Maria E. Matute-Bianchi (1986). Understanding Sociocultural Factors: Knowledge, Identity, and School Adjustment. In Beyond Language: Social and Cultural Factors in Schooling Language Minority Students. Los Angeles: Office of Bilingual Bicultural Education, pp. 73-142.

Ogbu, John U. (1978). Minority Education and Caste: The American System in Cross-Cultural Perspective. New York: Academic Press.

Orrenius, Pia and Madeline Zavodny (2005). Self-Selection among Undocumented Immigrants from Mexico. Journal of Development Economics 78 (1): 215-40.

Park, Robert E. (1914). "Racial Assimilation in Secondary Groups". American Journal of Sociology, 19, 606-23.

Passel, Jeffrey S. (2011). "Demography of Immigrant Youth: Past, Present, and Future". The Future of Children, 21(1), 19-41. 
Perlmann, Joel (1988). Ethnic Differences. Cambridge: Cambridge University Press.

Portes, Alejandro, and MacLeod Dag (1996). Educational progress of children of immigrants: The roles of class, ethnicity, and school context. Sociology of Education 69, 25575.

Ruiz-de-Velasco, Michael E. Fix, and Beatriz Clewell (2002). Overlooked and Underserved: Immigrant Students in U.S. Secondary Schools. The Urban Institute, Washington, DC.

Schwartz, Amy Ellen and Leanna Stiefel (2009). Immigrants and Inequality in Public Schools. Prepared for the project on Social Inequality and Educational Disadvantage.

Schwartz, Amy Ellen and Leanna Stiefel (2006). Is there a nativity gap? New evidence on the academic performance of immigrant students. Education Finance and Policy $1(1), 17-49$.

Stiefel, Leanna, Amy E. Schwartz and Dylan Conger (2010). Age of Entry and the High School Performance of Immigrant Youth. Journal of Urban Economics 67 (3), 303-14.

Suarez-Orozco, Marcelo M. (2000). Everything You Wanted to Know about Assimilation but Were Afraid to Ask. Daedalus, 129 (4), pp. 1-30.

Trueba, Henry (1987). Success or Failure? Learning and the Language Minority Student.Cambridge, MA: Newbury House.

White, Michael J. and Jennifer E. Glick (2009). Achieving Anew: How new immigrants do in American schools, jobs, and neighborhoods. Russell Sage Foundation. 
Figure 1

Student Distribution in Four Major Race/Ethnicity Categories by Immigrant Generation

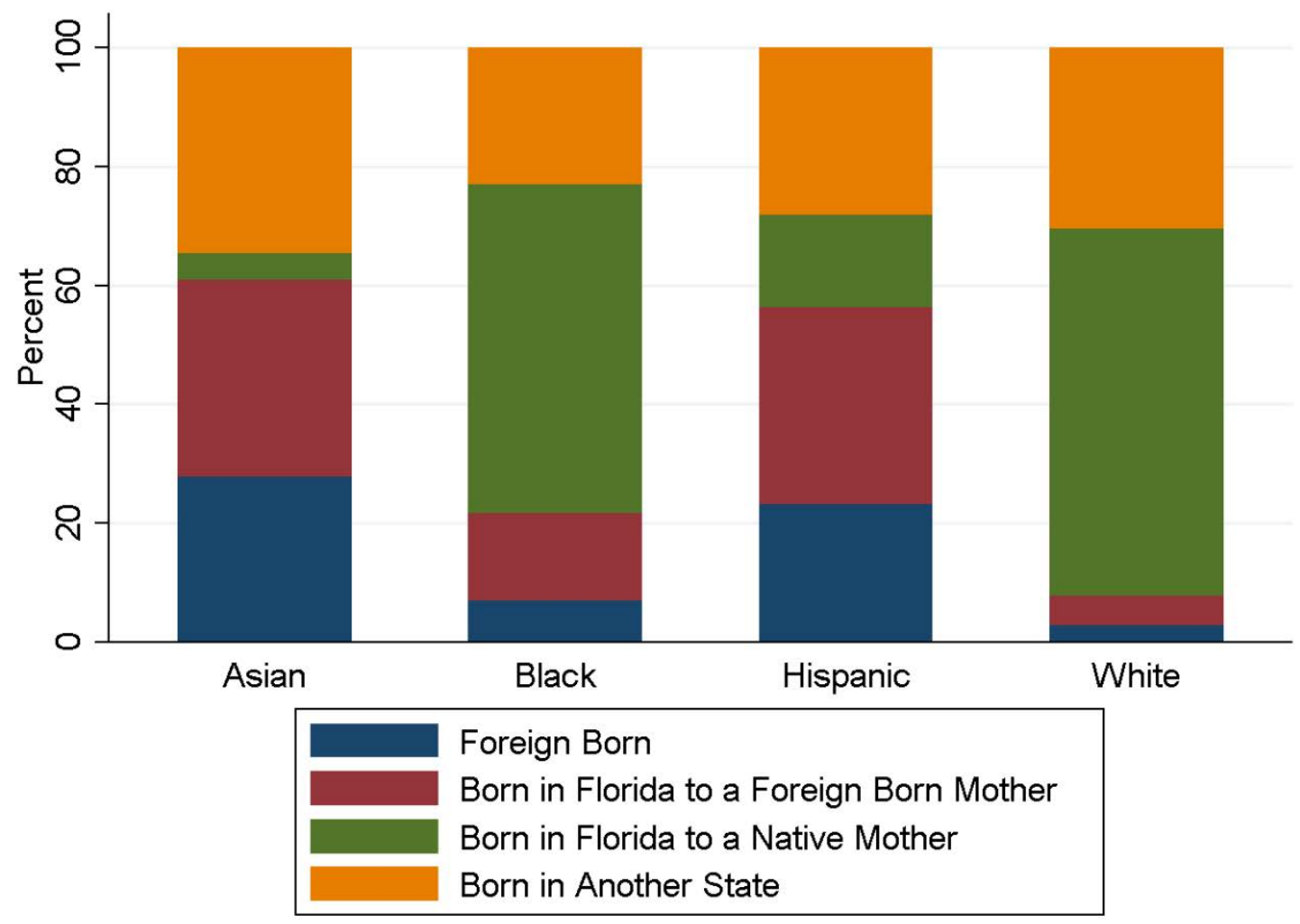


Figure 2 -Cross-Generational Differences in Eighth Grade Test Scores among Hispanic and Asian Students, Compared to Third Generation Whites, by Grade of Entry into the School System for the First Generation Immigrants

\section{(I) Reading - Hispanic}

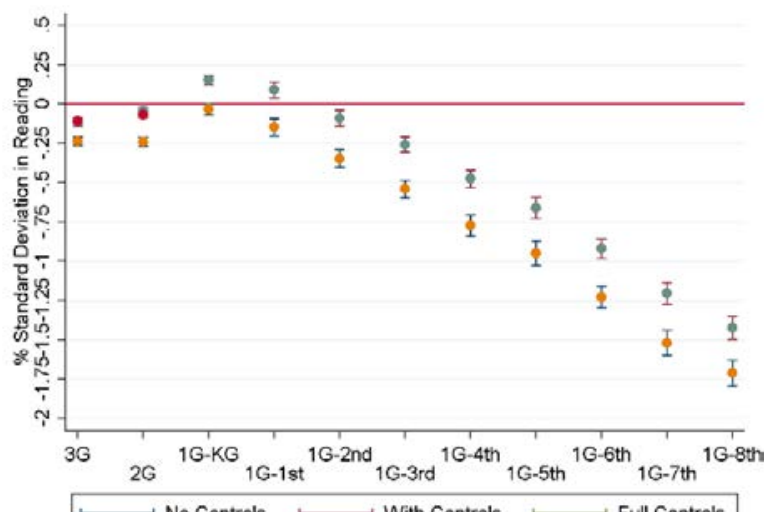

(III) Math - Hispanic

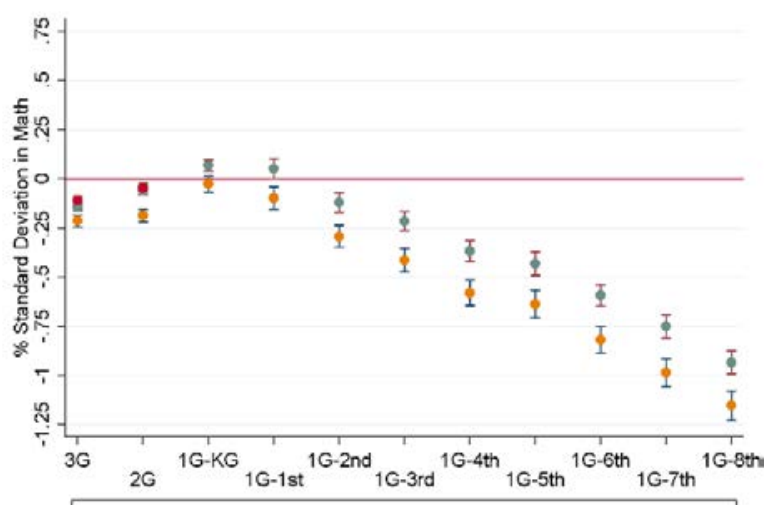

(II) Reading - Asian

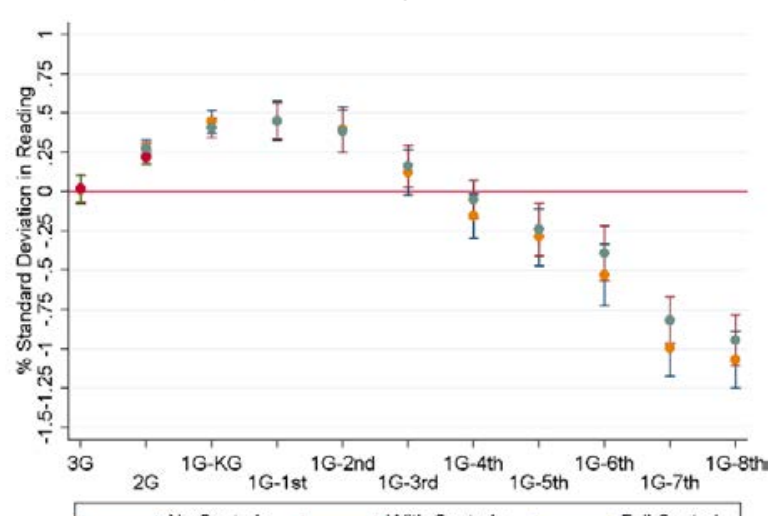

$\longmapsto$ No Controls $\longmapsto$ With Controls $\longmapsto$ Full Controls

(IV) Math - Asian

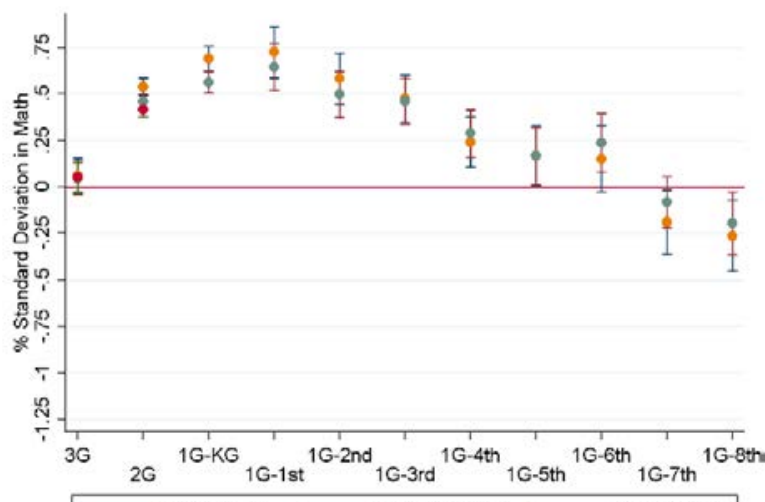

Notes: The "no controls", "with controls", and "full controls" specifications are obtained using models with only disability, gender, age controls, and cohort fixed-effects (no controls), controls for school by cohort fixed effects, English language spoken at home, and school lunch eligibility (with controls), and also maternal characteristics (full controls). The first generation indicators replaced by a series of first generation indicators based on grade of entry. Standard errors clustered at the school by year level. Capped spikes represent the 95 percent confidence interval for each coefficient. The regressions include 19,286 unique first generation Hispanic students, 21,998 unique second generation Hispanic students, 10,533 unique third generation Hispanic students, 2,375 unique first

generation Asian students, 2,534 unique second generation Asian students, 331 unique third generation Asian students, and 76,664 unique third generation white students. 
Figure 3 - Cross-Generational Differences in Eighth Grade Test Scores Compared to Third Generation Whites, by Grade of Entry into the School System for the First Generation Immigrants, Student Racial/Ethnic Identification versus Mother Racial/Ethnic Identification

(I) Reading - Hispanic

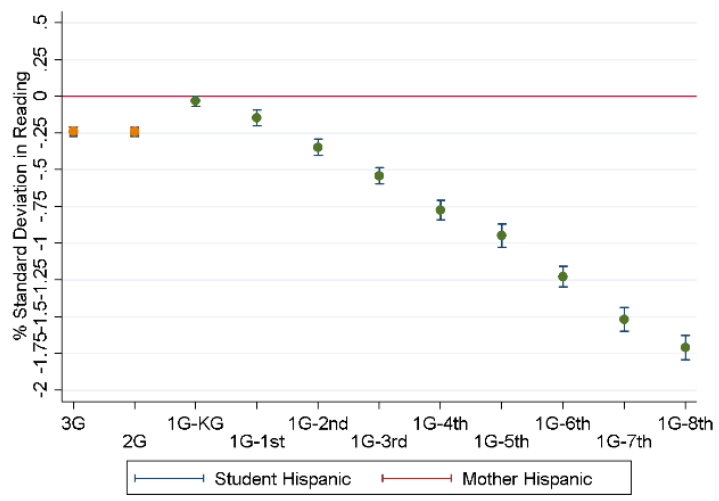

(III) Math - Hispanic

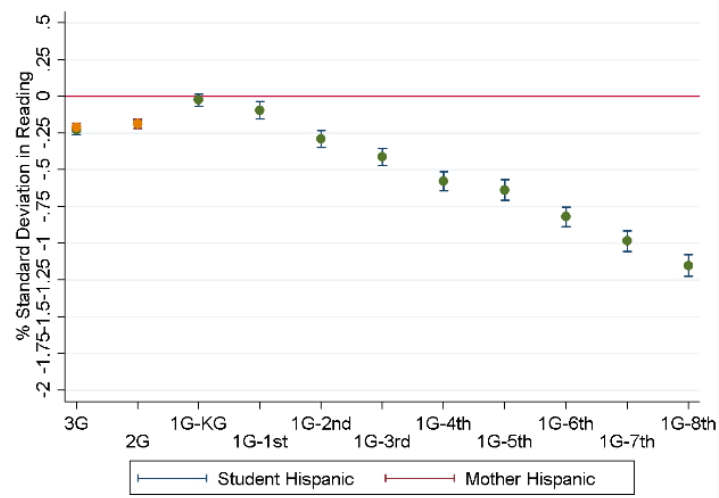

(II) Reading - Asian

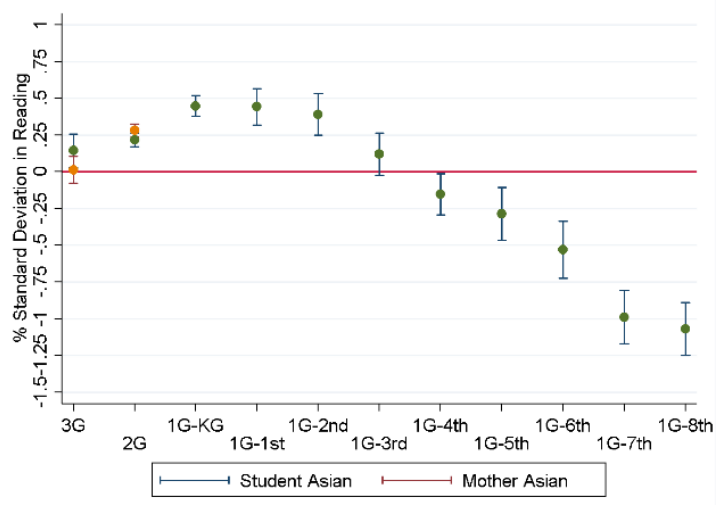

(IV) Math - Asian

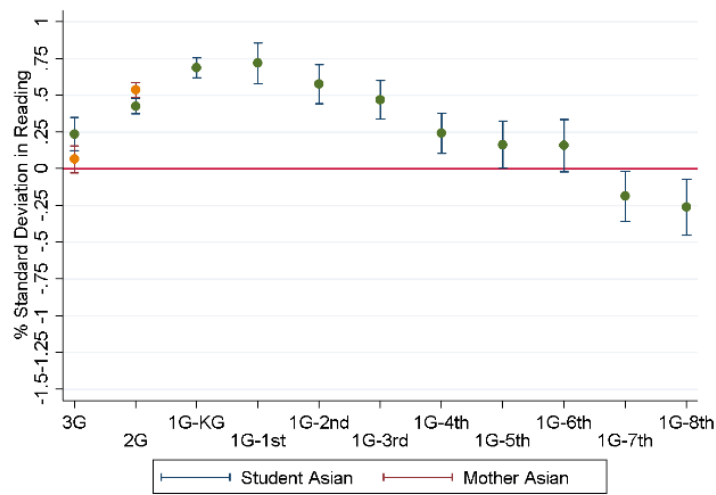

Notes: The estimates are obtained using the model that controls for disability, gender, age controls, and cohort fixed-effects. "Student Hispanic" and "Student Asian" specifications use the self-reported race/ethnicity whereas "Mother Hispanic" and "Mother Asian" specifications use the self-reported race/ethnicity of the mother to identify second and third generation Asian and Hispanic immigrants. Standard errors clustered at the school by year level. Capped spikes represent the 95 percent confidence interval for each coefficient. The regressions include 19,286 unique first generation Hispanic students, 28,870 unique second generation students with Hispanic mothers, 9,823 unique third generation students with Hispanic mothers, 2,375 unique first generation Asian students, 2,051 unique second generation students with Asian mothers, 233 unique third generation students with Asian mothers, 21,998 unique second generation Hispanic students, 10,533 unique third generation Hispanic students, 2,375 unique second generation Asian students, 331 unique third generation Asian students, and 79,052 unique third generation white students with non-Hispanic and non-Asian mothers. 
Figure 4 - Cross-Generational Differences in Disciplinary Incidents and Absences among Hispanic and Asian Students, Compared to Third Generation Whites, by Grade of Entry into the School System for the First Generation Immigrants
(I) Disciplinary Incidents - Hispanic
(II) Disciplinary Incidents - Asian
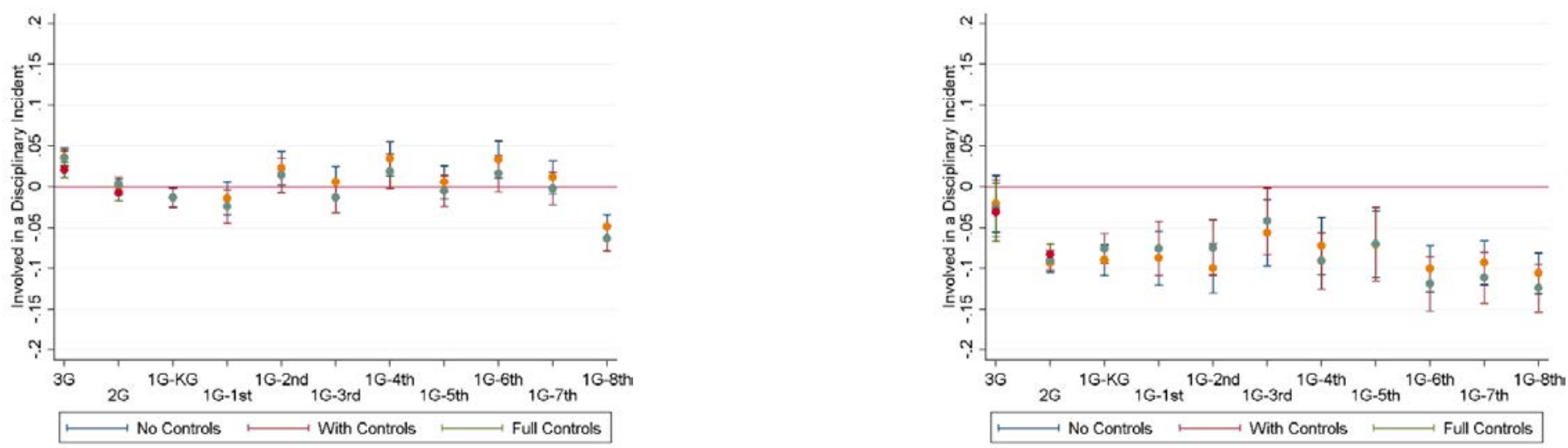

(III) \% Absent Days - Hispanic

(IV) \% Absent Days - Asian
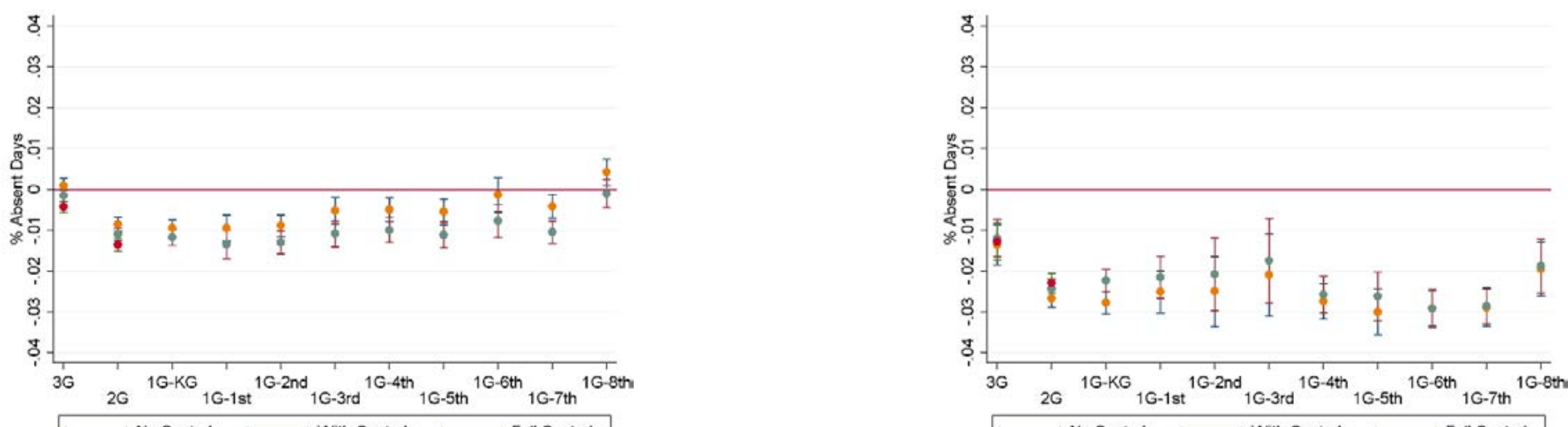

Notes: The "no controls", "with controls", and "full controls" specifications are obtained using models with only disability, gender, age controls, and cohort fixed-effects (no controls), controls for school by cohort fixed effects, English language spoken at home, and school lunch eligibility (with controls), and also maternal characteristics (full controls). The first generation indicators replaced by a series of first generation indicators based on grade of entry. Standard errors clustered at the school by year level. Capped spikes represent the 95 percent confidence interval for each coefficient. The regressions include 20,756 unique first generation Hispanic students, 22,457 unique second generation Hispanic students, 10,874 unique third generation Hispanic students, 2,552 unique first

generation Asian students, 2,572 unique second generation Asian students, 342 unique third generation Asian students, and 79,729 unique third generation white students. 
Figure 5 - Cross-Generational Differences in High School Graduation and Course-Taking among Hispanic and Asian Students, Compared to Third Generation Whites, by Grade of Entry into the School System for the First Generation Immigrants

(I) High School Graduation - Hispanics

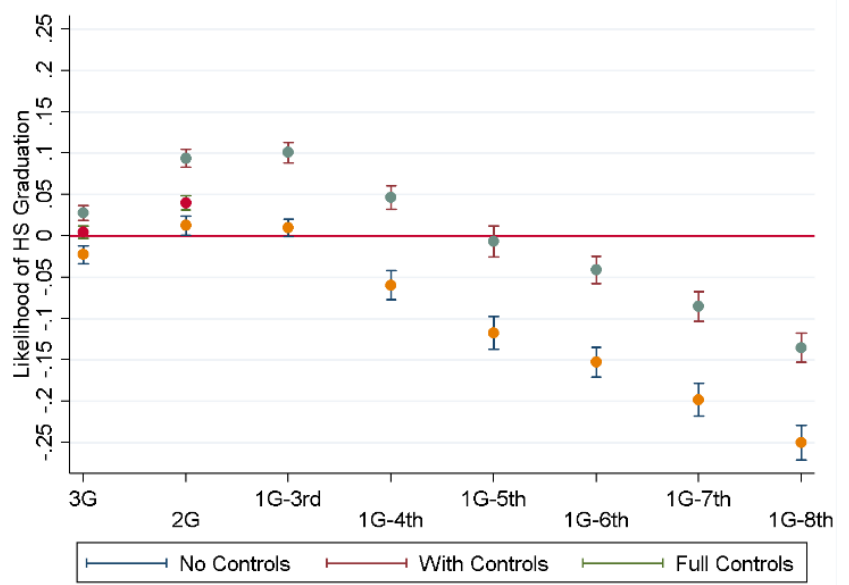

(III) Advanced Course-Taking - Hispanics

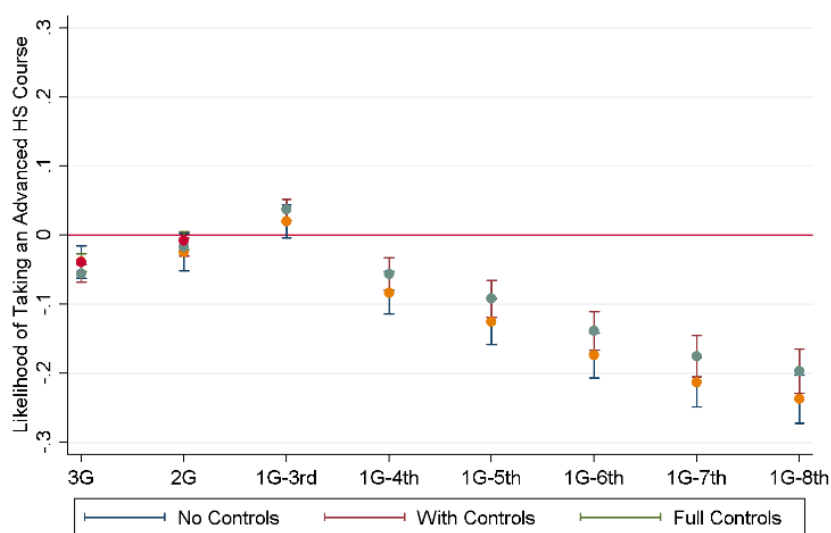

(II) High School Graduation - Asians

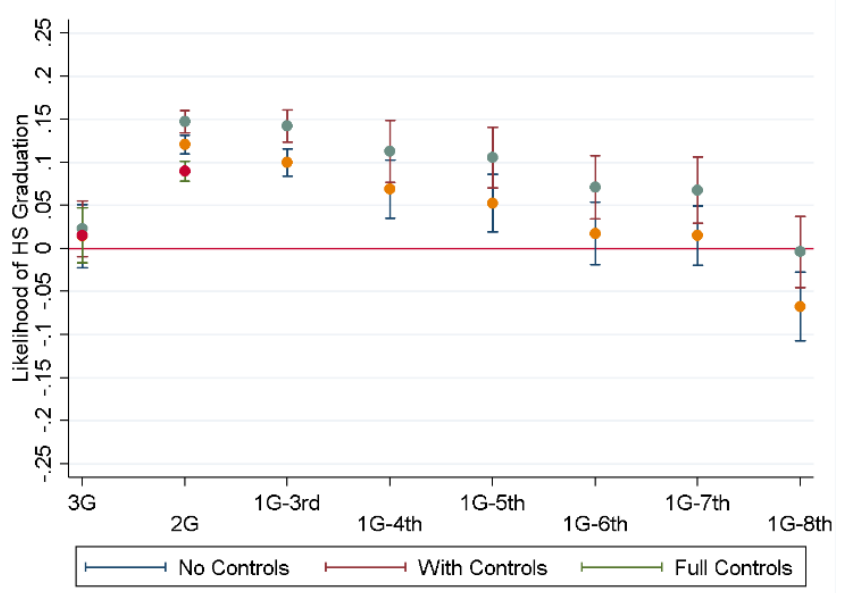

(IV) Advanced Course-Taking - Asians

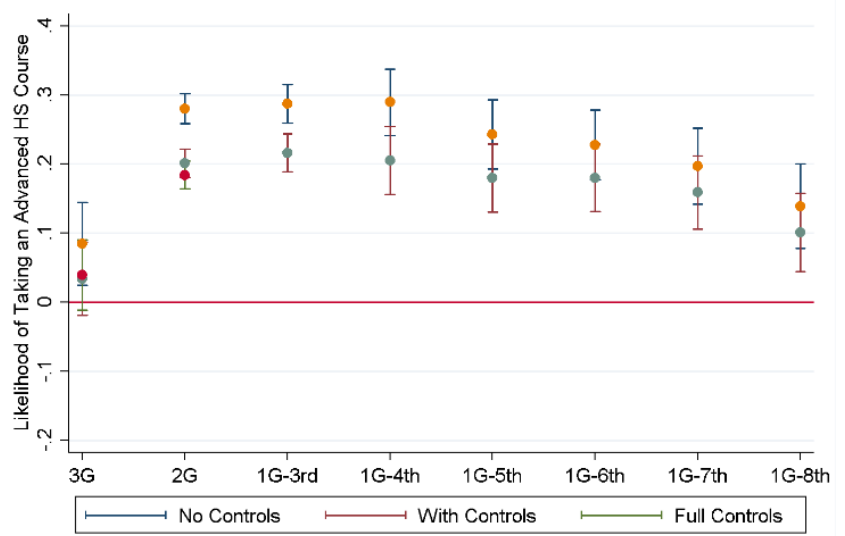

Notes: The "no controls", "with controls", and "full controls" specifications are obtained using models with only disability, gender, age controls, and cohort fixed-effects (no controls), controls for school by cohort fixed effects, English language spoken at home, and school lunch eligibility (with controls), and also maternal characteristics (full controls). The first generation indicators replaced by a series of first generation indicators based on grade of entry. Standard errors clustered at the school by year level. Capped spikes represent the 95 percent confidence interval for each coefficient. See Appendix Table A3 for number of observations in each group. 
Figure 6 - Cross-Generational Regression-Adjusted Trends in Student Test Scores over Grades among Hispanic and Asian Students, Compared to Third Generation Whites in grades 3 through 8, Conditional on Continuous Enrollment

(I) Reading - Hispanic

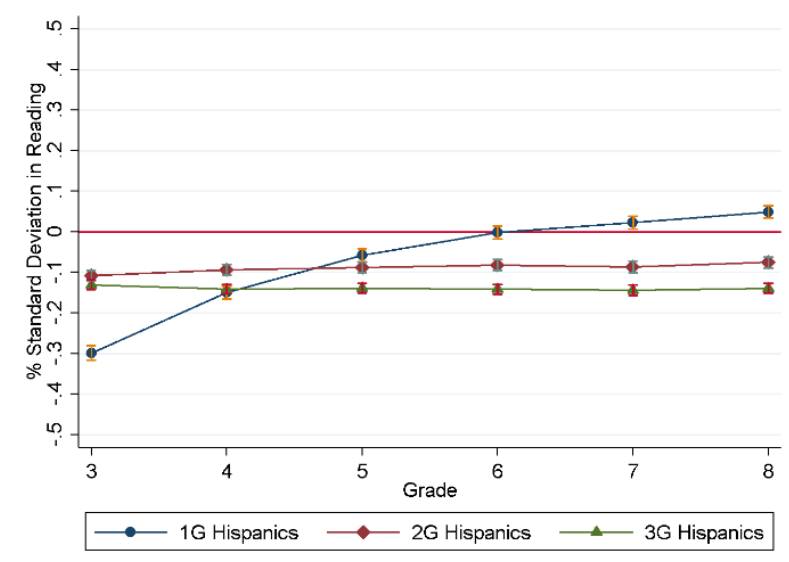

(III) Math - Hispanic

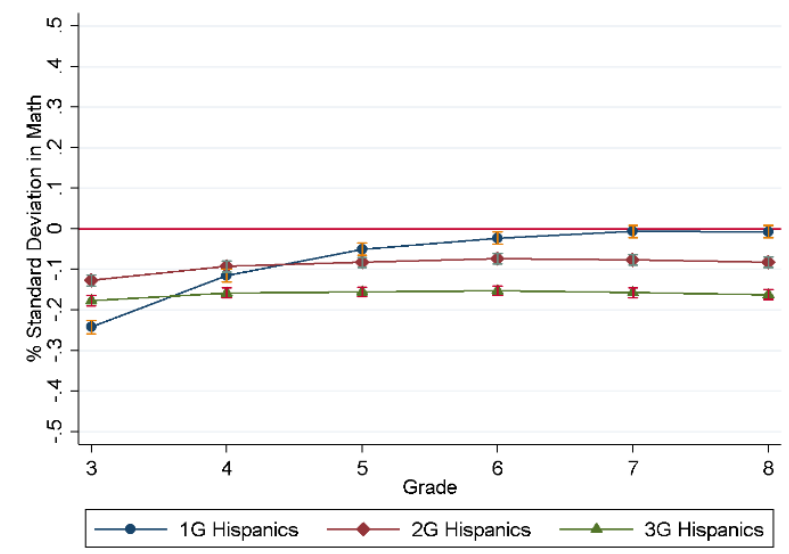

(II) Reading - Asian

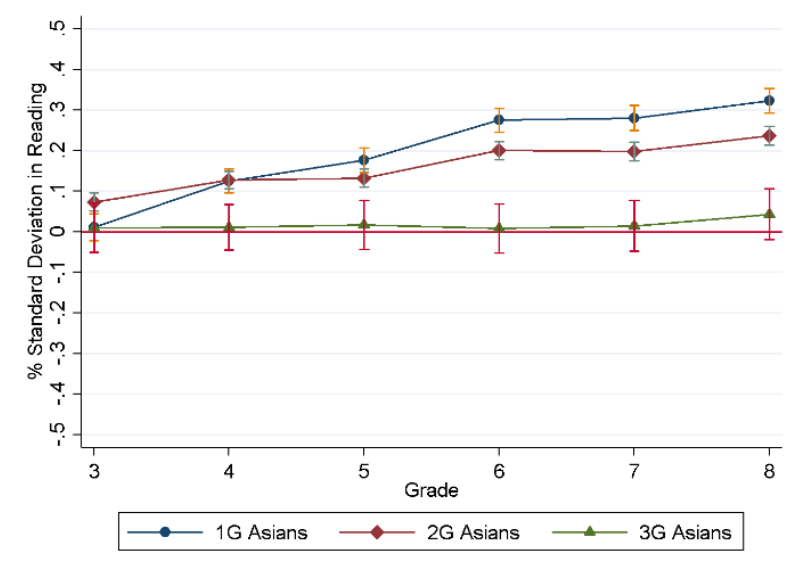

(IV) Math - Asian

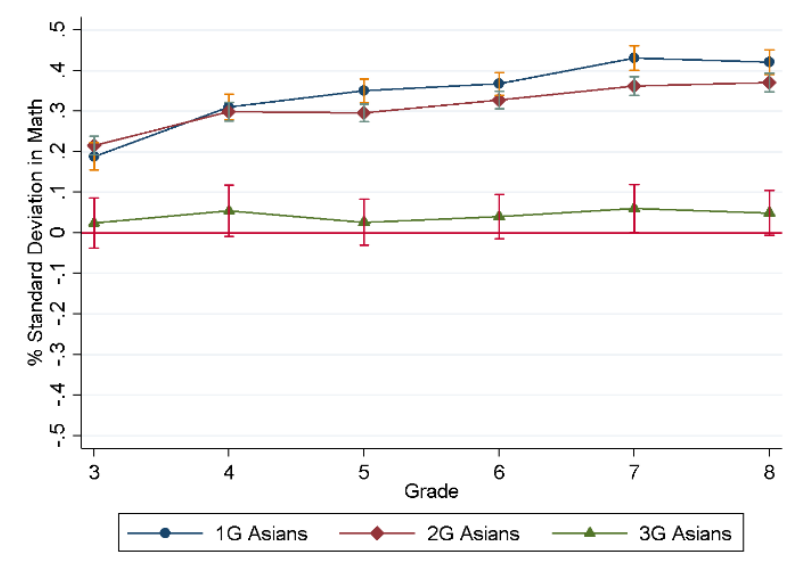

Notes: The estimated cross-generational differences among Asian, Hispanic, compared to the third generation white students are obtained using the covariates given in column (IV), Table A1, estimated separately for each given grade. Standard errors clustered at the school by year level. Capped spikes represent the 95 percent confidence interval for each estimated coefficient. The regressions include 34,325 unique early entering first generation Hispanic students, 61,439 unique second generation Hispanic students, 27,018 unique third generation Hispanic students, 3,321 unique early entering first generation Asian students, 6,307 unique second generation Asian students, 709 unique third generation Asian students, and 218,830 unique third generation white students. 
Figure 7 - Cross-Generational Regression-Adjusted Trends in Student Disciplinary Incidents and Absences over Grades among Hispanic and Asian Students, Compared to Third Generation Whites in grades 3 through 8, Conditional on Continuous Enrollment

(I) Disciplinary Incidents - Hispanic

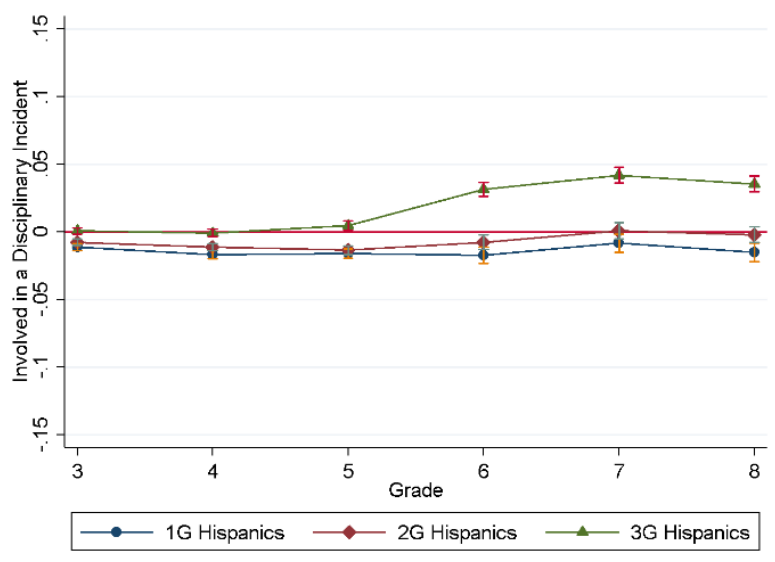

(III) \% Absent Days - Hispanic

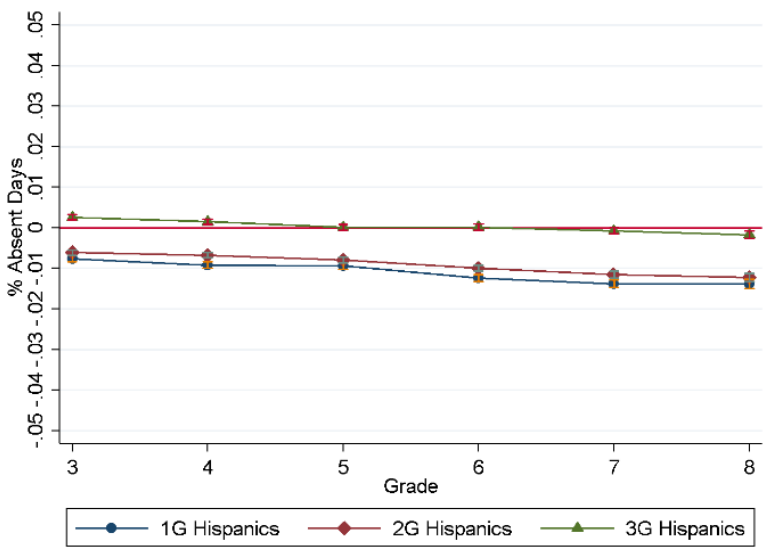

(II) Disciplinary Incidents - Asian

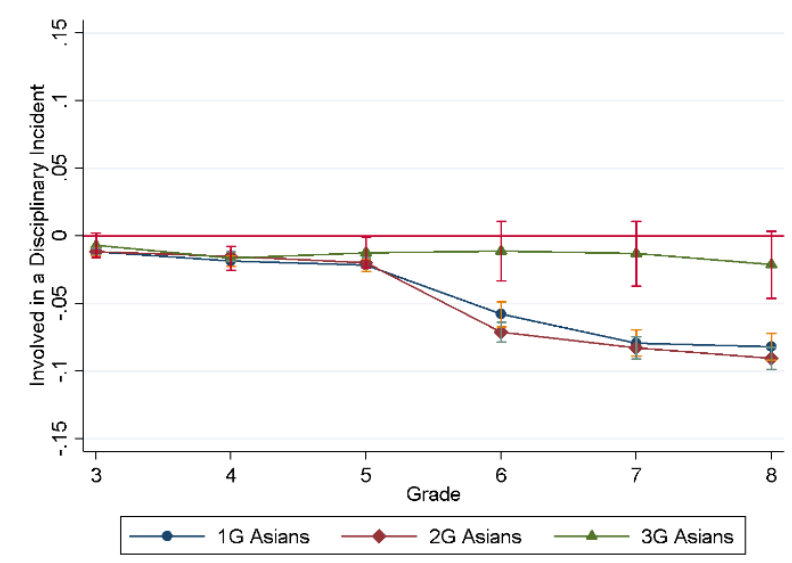

(IV) \% Absent Days - Asian

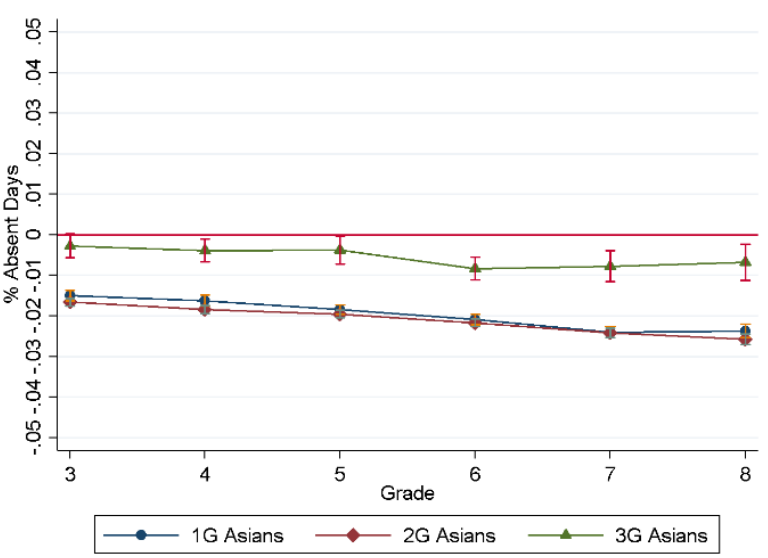

Notes: The estimated cross-generational differences among Asian, Hispanic, compared to the third generation white students are obtained using the covariates given in column (IV), Table A1, estimated separately for each given grade. Standard errors clustered at the school by year level. Capped spikes represent the 95 percent confidence interval for each estimated coefficient. The regressions include 37,402 unique early entering first generation Hispanic students, 63,251 unique second generation Hispanic students, 28,406 unique third generation Hispanic students, 3,694 unique early entering first generation Asian students, 6,457 unique second generation Asian students, 754 unique third generation Asian students, and 234,095 unique third generation white students. 
Table 1 - Country of Birth among First Generation Asian and Hispanic Immigrants

\begin{tabular}{|c|c|c|c|c|c|}
\hline \multicolumn{3}{|l|}{ Hispanic Students } & \multicolumn{3}{|l|}{ Asian Students } \\
\hline Country of Birth & $\begin{array}{c}\text { Percent of First } \\
\text { Generation Hispanics }\end{array}$ & $\begin{array}{c}\text { Number of } \\
\text { unique students }\end{array}$ & Country of Birth & $\begin{array}{c}\text { Percent of First } \\
\text { Generation Asians }\end{array}$ & $\begin{array}{c}\text { Number of } \\
\text { unique students }\end{array}$ \\
\hline Cuba & 22.18 & 41,964 & Philippines & 16.04 & 3,914 \\
\hline Mexico & 17.32 & 32,766 & China & 13.42 & 3,275 \\
\hline Colombia & 12.02 & 22,744 & India & 13.22 & 3,225 \\
\hline Puerto Rico & 10.86 & 20,541 & South Korea & 9.32 & 2,273 \\
\hline Venezuela & 7.31 & 13,827 & Vietnam & 8.02 & 1,956 \\
\hline Dominican Republic & 3.93 & 7,438 & Pakistan & 4.36 & 1,064 \\
\hline Honduras & 3.79 & 7,164 & Japan & 3.25 & 793 \\
\hline Peru & 3.74 & 7,082 & Bangladesh & 3.04 & 741 \\
\hline Argentina & 3.18 & 6,012 & Thailand & 2.50 & 610 \\
\hline Ecuador & 2.17 & 4,111 & Canada & 2.48 & 605 \\
\hline Guatemala & 2.01 & 3,804 & Guyana & 1.87 & 456 \\
\hline Nicaragua & 1.75 & 3,304 & Burma & 1.31 & 319 \\
\hline Brazil & 1.37 & 2,586 & Taiwan & 0.99 & 241 \\
\hline Spain & 1.35 & 2,549 & Other & 20.19 & 4,926 \\
\hline Other & 7.04 & 13,314 & & & \\
\hline
\end{tabular}

Notes: The distribution of country of birth among first generation immigrants is obtained using the set of students who were born outside of the U.S. between 1992 and 2002, and subsequently attend $8^{\text {th }}$ grade in a Florida public school between 2002-03 and 2011-12 school years. 
Table 2 - Cross-generational Differences in Student Outcomes and Characteristics - Hispanic Immigrants

\begin{tabular}{|c|c|c|c|c|c|}
\hline & $\begin{array}{l}\text { White } \\
\text { third Gen. }\end{array}$ & $\begin{array}{l}\text { Hispanic } \\
\text { first Gen. } \\
\text { Late Entering }\end{array}$ & $\begin{array}{c}\text { Hispanic } \\
\text { first Gen. } \\
\text { Early Entering }\end{array}$ & $\begin{array}{c}\text { Hispanic } \\
\text { second Gen. }\end{array}$ & $\begin{array}{l}\text { Hispanic } \\
\text { third Gen. }\end{array}$ \\
\hline FCAT reading score - eighth grade & $\begin{array}{c}0.265 \\
(0.909)\end{array}$ & $\begin{array}{l}-0.603 \\
(1.168)\end{array}$ & $\begin{array}{c}0.0750 \\
(0.964)\end{array}$ & $\begin{array}{l}-0.0118 \\
(0.917)\end{array}$ & $\begin{array}{l}-0.0159 \\
(0.926)\end{array}$ \\
\hline FCAT math score - eighth grade & $\begin{array}{c}0.264 \\
(0.884)\end{array}$ & $\begin{array}{l}-0.383 \\
(1.110)\end{array}$ & $\begin{array}{c}0.0865 \\
(0.950)\end{array}$ & $\begin{array}{r}0.0159 \\
(0.899)\end{array}$ & $\begin{array}{l}-0.0117 \\
(0.918)\end{array}$ \\
\hline Disciplinary incident - eighth grade & $\begin{array}{c}0.202 \\
(0.401)\end{array}$ & $\begin{array}{c}0.191 \\
(0.393)\end{array}$ & $\begin{array}{c}0.200 \\
(0.400)\end{array}$ & $\begin{array}{c}0.204 \\
(0.403)\end{array}$ & $\begin{array}{c}0.246 \\
(0.430)\end{array}$ \\
\hline$\%$ Absent days - eighth grade & $\begin{array}{c}0.0636 \\
(0.0768)\end{array}$ & $\begin{array}{c}0.0569 \\
(0.0733)\end{array}$ & $\begin{array}{c}0.0545 \\
(0.0670)\end{array}$ & $\begin{array}{c}0.0562 \\
(0.0722)\end{array}$ & $\begin{array}{c}0.0676 \\
(0.0823)\end{array}$ \\
\hline Graduated from HS & $\begin{array}{c}0.591 \\
(0.492)\end{array}$ & $\begin{array}{c}0.431 \\
(0.495)\end{array}$ & $\begin{array}{c}0.535 \\
(0.499)\end{array}$ & $\begin{array}{c}0.562 \\
(0.496)\end{array}$ & $\begin{array}{c}0.522 \\
(0.500)\end{array}$ \\
\hline Took an advanced course in HS & $\begin{array}{c}0.508 \\
(0.500)\end{array}$ & $\begin{array}{c}0.376 \\
(0.484)\end{array}$ & $\begin{array}{c}0.532 \\
(0.499)\end{array}$ & $\begin{array}{c}0.483 \\
(0.500)\end{array}$ & $\begin{array}{c}0.470 \\
(0.499)\end{array}$ \\
\hline FRPL Eligible & $\begin{array}{c}0.315 \\
(0.464)\end{array}$ & $\begin{array}{c}0.750 \\
(0.433)\end{array}$ & $\begin{array}{c}0.739 \\
(0.439)\end{array}$ & $\begin{array}{c}0.698 \\
(0.459)\end{array}$ & $\begin{array}{l}0.585 \\
(0.493)\end{array}$ \\
\hline Limited English proficient - eighth grade & $\begin{array}{l}0.000265 \\
(0.0163)\end{array}$ & $\begin{array}{c}0.559 \\
(0.497)\end{array}$ & $\begin{array}{r}0.0932 \\
(0.291)\end{array}$ & $\begin{array}{r}0.0369 \\
(0.189)\end{array}$ & $\begin{array}{l}0.0213 \\
(0.144)\end{array}$ \\
\hline Limited English proficient - Ever & $\begin{array}{c}0.00338 \\
(0.0581)\end{array}$ & $\begin{array}{c}0.829 \\
(0.377)\end{array}$ & $\begin{array}{c}0.839 \\
(0.368)\end{array}$ & $\begin{array}{c}0.597 \\
(0.490)\end{array}$ & $\begin{array}{c}0.272 \\
(0.445)\end{array}$ \\
\hline English Non-Native & $\begin{array}{l}0.0102 \\
(0.100)\end{array}$ & $\begin{array}{c}0.944 \\
(0.231)\end{array}$ & $\begin{array}{c}0.953 \\
(0.211)\end{array}$ & $\begin{array}{c}0.838 \\
(0.369)\end{array}$ & $\begin{array}{c}0.477 \\
(0.499)\end{array}$ \\
\hline Special education & $\begin{array}{c}0.132 \\
(0.339)\end{array}$ & $\begin{array}{r}0.0513 \\
(0.221)\end{array}$ & $\begin{array}{c}0.112 \\
(0.316)\end{array}$ & $\begin{array}{c}0.134 \\
(0.341)\end{array}$ & $\begin{array}{l}0.148 \\
(0.355)\end{array}$ \\
\hline Mother - Less than HS & $\begin{array}{c}0.159 \\
(0.366)\end{array}$ & & & $\begin{array}{c}0.339 \\
(0.473)\end{array}$ & $\begin{array}{c}0.303 \\
(0.460)\end{array}$ \\
\hline Mother - HS graduate & $\begin{array}{c}0.386 \\
(0.487)\end{array}$ & & & $\begin{array}{c}0.362 \\
(0.480)\end{array}$ & $\begin{array}{c}0.350 \\
(0.477)\end{array}$ \\
\hline Mother - Some college & $\begin{array}{c}0.258 \\
(0.438)\end{array}$ & & & $\begin{array}{c}0.183 \\
(0.387)\end{array}$ & $\begin{array}{c}0.233 \\
(0.423)\end{array}$ \\
\hline Mother - Bachelor's or more & $\begin{array}{c}0.194 \\
(0.396)\end{array}$ & & & $\begin{array}{c}0.114 \\
(0.317)\end{array}$ & $\begin{array}{c}0.111 \\
(0.314)\end{array}$ \\
\hline Mother married & $\begin{array}{c}0.773 \\
(0.419) \\
\end{array}$ & & & $\begin{array}{c}0.675 \\
(0.468) \\
\end{array}$ & $\begin{array}{c}0.612 \\
(0.487) \\
\end{array}$ \\
\hline
\end{tabular}

Notes: Standard deviations are given in parentheses. See Appendix Tables A1, A2, and A3 for the numbers of unique students in each category given in columns. 
Table 3 - Cross-generational Differences in eighth Grade Student Outcomes and Characteristics - Asian Immigrants

\begin{tabular}{|c|c|c|c|c|c|}
\hline & $\begin{array}{c}\text { White } \\
\text { third Gen. }\end{array}$ & $\begin{array}{c}\text { Asian } \\
\text { first Gen. } \\
\text { Late Entering }\end{array}$ & $\begin{array}{c}\text { Asian } \\
\text { first Gen. } \\
\text { Early Entering }\end{array}$ & $\begin{array}{c}\text { Asian } \\
\text { second Gen. }\end{array}$ & $\begin{array}{l}\text { Asian } \\
\text { third Gen. }\end{array}$ \\
\hline FCAT reading score - eighth grade & $\begin{array}{c}0.265 \\
(0.909)\end{array}$ & $\begin{array}{c}0.0366 \\
(1.167)\end{array}$ & $\begin{array}{c}0.674 \\
(0.960)\end{array}$ & $\begin{array}{c}0.593 \\
(0.921)\end{array}$ & $\begin{array}{c}0.363 \\
(0.885)\end{array}$ \\
\hline FCAT math score - eighth grade & $\begin{array}{c}0.264 \\
(0.884)\end{array}$ & $\begin{array}{c}0.475 \\
(1.046)\end{array}$ & $\begin{array}{c}0.837 \\
(0.945)\end{array}$ & $\begin{array}{c}0.780 \\
(0.914)\end{array}$ & $\begin{array}{c}0.396 \\
(0.882)\end{array}$ \\
\hline Disciplinary incident - eighth grade & $\begin{array}{c}0.202 \\
(0.401)\end{array}$ & $\begin{array}{c}0.0691 \\
(0.254)\end{array}$ & $\begin{array}{c}0.0825 \\
(0.275)\end{array}$ & $\begin{array}{c}0.0859 \\
(0.280)\end{array}$ & $\begin{array}{c}0.151 \\
(0.358)\end{array}$ \\
\hline$\%$ Absent days - eighth grade & $\begin{array}{c}0.0636 \\
(0.0768)\end{array}$ & $\begin{array}{c}0.0314 \\
(0.0571)\end{array}$ & $\begin{array}{c}0.0311 \\
(0.0471)\end{array}$ & $\begin{array}{c}0.0291 \\
(0.0470)\end{array}$ & $\begin{array}{c}0.0513 \\
(0.0712)\end{array}$ \\
\hline Graduated from HS & $\begin{array}{c}0.591 \\
(0.492)\end{array}$ & $\begin{array}{c}0.575 \\
(0.494)\end{array}$ & $\begin{array}{c}0.708 \\
(0.455)\end{array}$ & $\begin{array}{c}0.758 \\
(0.429)\end{array}$ & $\begin{array}{c}0.628 \\
(0.484)\end{array}$ \\
\hline Took an advanced course in HS & $\begin{array}{c}0.508 \\
(0.500)\end{array}$ & $\begin{array}{c}0.749 \\
(0.433)\end{array}$ & $\begin{array}{c}0.811 \\
(0.391)\end{array}$ & $\begin{array}{c}0.805 \\
(0.396)\end{array}$ & $\begin{array}{c}0.602 \\
(0.490)\end{array}$ \\
\hline FRPL Eligible & $\begin{array}{c}0.315 \\
(0.464)\end{array}$ & $\begin{array}{c}0.413 \\
(0.492)\end{array}$ & $\begin{array}{c}0.357 \\
(0.479)\end{array}$ & $\begin{array}{c}0.334 \\
(0.472)\end{array}$ & $\begin{array}{c}0.351 \\
(0.478)\end{array}$ \\
\hline Limited English proficient - eighth grade & $\begin{array}{l}0.000265 \\
(0.0163)\end{array}$ & $\begin{array}{c}0.370 \\
(0.483)\end{array}$ & $\begin{array}{c}0.0374 \\
(0.190)\end{array}$ & $\begin{array}{c}0.0152 \\
(0.122)\end{array}$ & $\begin{array}{r}0.00167 \\
(0.0408)\end{array}$ \\
\hline Limited English proficient - Ever & $\begin{array}{c}0.00338 \\
(0.0581)\end{array}$ & $\begin{array}{c}0.561 \\
(0.496)\end{array}$ & $\begin{array}{c}0.475 \\
(0.499)\end{array}$ & $\begin{array}{c}0.303 \\
(0.460)\end{array}$ & $\begin{array}{c}0.0501 \\
(0.218)\end{array}$ \\
\hline English Non-Native & $\begin{array}{r}0.0102 \\
(0.100)\end{array}$ & $\begin{array}{c}0.725 \\
(0.446)\end{array}$ & $\begin{array}{c}0.662 \\
(0.473)\end{array}$ & $\begin{array}{c}0.568 \\
(0.495)\end{array}$ & $\begin{array}{c}0.112 \\
(0.315)\end{array}$ \\
\hline Special education & $\begin{array}{c}0.132 \\
(0.339)\end{array}$ & $\begin{array}{c}0.0251 \\
(0.156)\end{array}$ & $\begin{array}{c}0.0490 \\
(0.216)\end{array}$ & $\begin{array}{r}0.0570 \\
(0.232)\end{array}$ & $\begin{array}{c}0.0860 \\
(0.280)\end{array}$ \\
\hline Mother - Less than HS & $\begin{array}{c}0.159 \\
(0.366)\end{array}$ & & & $\begin{array}{c}0.138 \\
(0.345)\end{array}$ & $\begin{array}{c}0.179 \\
(0.383)\end{array}$ \\
\hline Mother - HS graduate & $\begin{array}{c}0.386 \\
(0.487)\end{array}$ & & & $\begin{array}{c}0.316 \\
(0.465)\end{array}$ & $\begin{array}{c}0.311 \\
(0.463)\end{array}$ \\
\hline Mother - Some college & $\begin{array}{c}0.258 \\
(0.438)\end{array}$ & & & $\begin{array}{c}0.198 \\
(0.398)\end{array}$ & $\begin{array}{c}0.298 \\
(0.458)\end{array}$ \\
\hline Mother - Bachelor's or more & $\begin{array}{c}0.194 \\
(0.396)\end{array}$ & & & $\begin{array}{c}0.338 \\
(0.473)\end{array}$ & $\begin{array}{c}0.208 \\
(0.406)\end{array}$ \\
\hline Mother married & $\begin{array}{c}0.773 \\
(0.419)\end{array}$ & & & $\begin{array}{c}0.886 \\
(0.318)\end{array}$ & $\begin{array}{c}0.693 \\
(0.462)\end{array}$ \\
\hline
\end{tabular}

Notes: Standard deviations are given in parentheses. See Appendix Tables A1, A2, and A3 for the numbers of unique students in each category given in columns. 
Table 4 - Cross-Generational Differences in School Choice and Advanced Course-Taking in High School

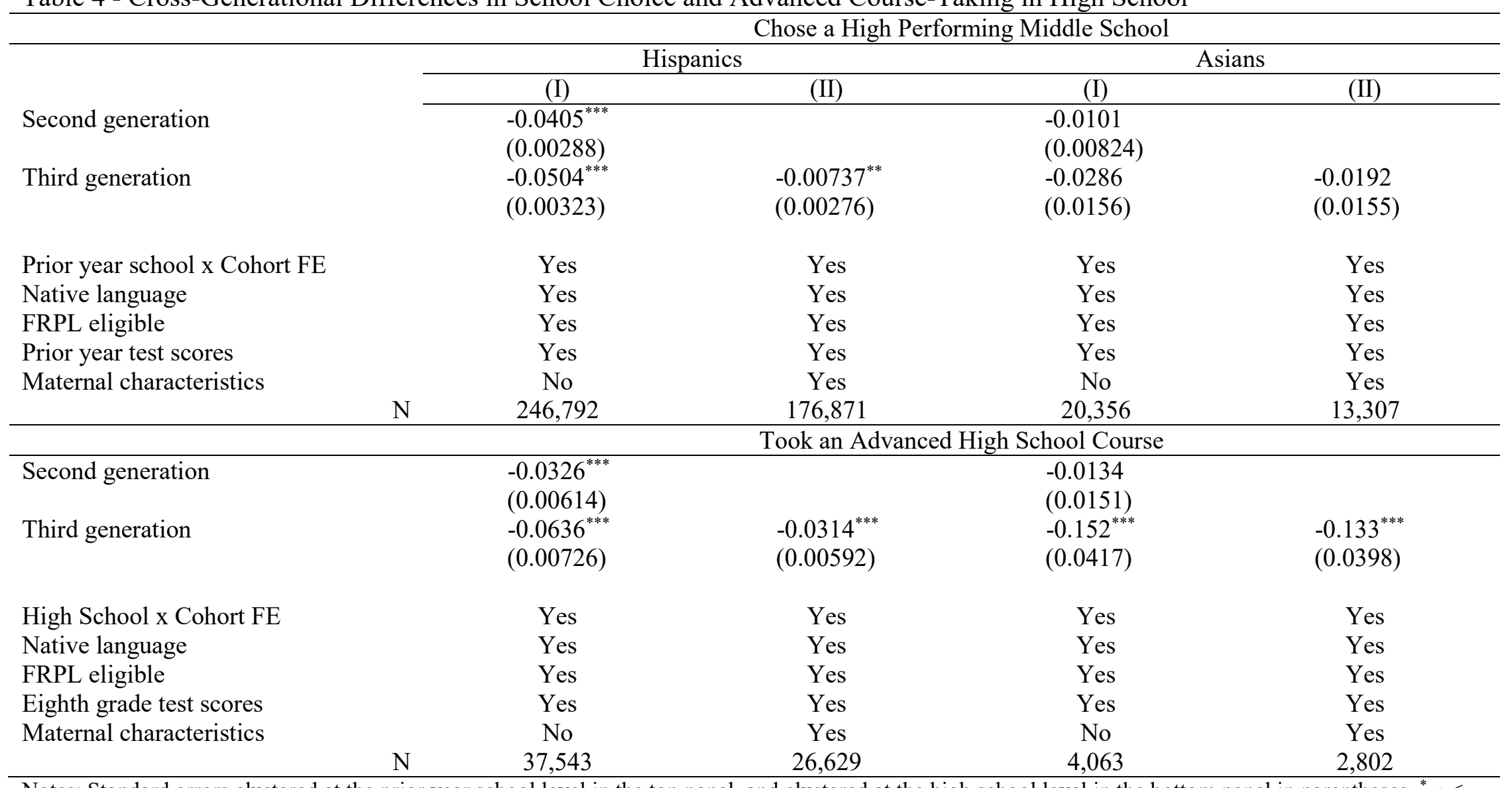

Notes: Standard errors clustered at the prior year school level in the top panel, and clustered at the high school level in the bottom panel in parentheses, ${ }^{*} p<$ $0.05,{ }^{* *} p<0.01,{ }^{* * *} p<0.001$. All models control for gender, age, special education status in addition to the covariates listed. 
APPENDIX A

Table A1 - Regression Adjusted Cross-Generational Differences in Hispanic and Asian Eighth Grade Test Scores, Compared to Third Generation White Students

\begin{tabular}{|c|c|c|c|c|c|c|}
\hline & & \multicolumn{5}{|c|}{ Reading Scores } \\
\hline & & $(1)$ & $(2)$ & $(3)$ & (4) & (5) \\
\hline \multicolumn{7}{|l|}{ Hispanics - } \\
\hline & Late Entering First Gen. & $-1.167^{* * *}$ & $-1.093^{* * *}$ & $-0.943^{* * *}$ & $-0.857^{* * *}$ & \\
\hline & & $(0.0147)$ & $(0.0112)$ & $(0.0119)$ & $(0.0116)$ & \\
\hline & Early Entering First Gen. & $-0.170^{* * *}$ & $-0.162^{* * *}$ & -0.0110 & $0.0579^{* * *}$ & \\
\hline & & $(0.00863)$ & $(0.00570)$ & $(0.00664)$ & $(0.00647)$ & \\
\hline & Second Generation & $-0.258^{* * *}$ & $-0.230^{* * *}$ & $-0.100^{* * *}$ & $-0.0392^{* * *}$ & $-0.0626^{* * *}$ \\
\hline & & $(0.00733)$ & $(0.00507)$ & $(0.00596)$ & $(0.00579)$ & $(0.00560)$ \\
\hline & Third Generation & $-0.251^{* * *}$ & $-0.233^{* * *}$ & $-0.161^{* * *}$ & $-0.114^{* * *}$ & $-0.106^{* * *}$ \\
\hline & & $(0.00729)$ & $(0.00523)$ & $(0.00552)$ & $(0.00537)$ & $(0.00524)$ \\
\hline \multicolumn{7}{|l|}{ Asians - } \\
\hline & Late Entering First Gen. & $-0.464^{* * *}$ & $-0.495^{* * *}$ & $-0.375^{* * *}$ & $-0.355^{* * *}$ & \\
\hline & & $(0.0232)$ & $(0.0207)$ & $(0.0205)$ & $(0.0199)$ & \\
\hline & Early Entering First Gen. & $0.302^{* * *}$ & $0.202^{* * *}$ & $0.313^{* * *}$ & $0.317^{* * *}$ & \\
\hline & & $(0.0139)$ & $(0.0126)$ & $(0.0130)$ & $(0.0127)$ & \\
\hline & Second Generation & $0.223^{* * *}$ & $0.127^{* * *}$ & $0.222^{* * *}$ & $0.227^{* * *}$ & $0.177^{* * *}$ \\
\hline & & $(0.0111)$ & $(0.00964)$ & $(0.00989)$ & $(0.00977)$ & $(0.00958)$ \\
\hline & Third Generation & 0.0293 & -0.0150 & 0.00475 & 0.0207 & 0.0211 \\
\hline & & $(0.0253)$ & $(0.0248)$ & $(0.0248)$ & $(0.0244)$ & $(0.0238)$ \\
\hline \multicolumn{7}{|c|}{ Math Scores } \\
\hline \multicolumn{7}{|l|}{ Hispanics - } \\
\hline & Late Entering First Gen. & $-0.892^{* * *}$ & $-0.831^{* * *}$ & $-0.741^{* * *}$ & $-0.663^{* * *}$ & \\
\hline & & $(0.0132)$ & $(0.00919)$ & $(0.00977)$ & $(0.00960)$ & \\
\hline & Early Entering First Gen. & $-0.164^{* * *}$ & $-0.170^{* * *}$ & $-0.0793^{* * *}$ & $-0.0167^{* *}$ & \\
\hline & & $(0.00975)$ & $(0.00541)$ & $(0.00643)$ & $(0.00628)$ & \\
\hline & Second Generation & $-0.229^{* * *}$ & $-0.206^{* * *}$ & $-0.128^{* * *}$ & $-0.0728^{* * *}$ & $-0.0661^{* * *}$ \\
\hline & & $(0.00766)$ & $(0.00455)$ & $(0.00555)$ & $(0.00542)$ & $(0.00548)$ \\
\hline & Third Generation & $-0.245^{* * *}$ & $-0.236^{* * *}$ & $-0.193^{* * *}$ & $-0.149^{* * *}$ & $-0.124^{* * *}$ \\
\hline & & $(0.00749)$ & $(0.00511)$ & $(0.00541)$ & $(0.00526)$ & $(0.00514)$ \\
\hline \multicolumn{7}{|l|}{ Asians - } \\
\hline & Late Entering First Gen. & $\begin{array}{c}0.0216 \\
(0.0210)\end{array}$ & $\begin{array}{l}-0.0202 \\
(0.0181)\end{array}$ & $\begin{array}{c}0.0526^{* a} \\
(0.0182)\end{array}$ & $\begin{array}{c}0.0710 \\
(0.0177)\end{array}$ & \\
\hline
\end{tabular}




\begin{tabular}{|c|c|c|c|c|c|}
\hline Early Entering First Gen. & $\begin{array}{c}0.467^{* * *} \\
(0.0146)\end{array}$ & $\begin{array}{c}0.348^{* * *} \\
(0.0126)\end{array}$ & $\begin{array}{c}0.415^{* * *} \\
(0.0131)\end{array}$ & $\begin{array}{c}0.418^{* * *} \\
(0.0128)\end{array}$ & \\
\hline Second Generation & $\begin{array}{c}0.402^{* * *} \\
(0.0116)\end{array}$ & $\begin{array}{c}0.294^{* * *} \\
(0.00954)\end{array}$ & $\begin{array}{c}0.351^{* * *} \\
(0.00984)\end{array}$ & $\begin{array}{c}0.356^{* * *} \\
(0.00975)\end{array}$ & $\begin{array}{c}0.318^{* * * *} \\
(0.00967)\end{array}$ \\
\hline Third Generation & $\begin{array}{c}0.0590^{*} \\
(0.0247)\end{array}$ & $\begin{array}{c}0.0132 \\
(0.0233)\end{array}$ & $\begin{array}{c}0.0234 \\
(0.0233)\end{array}$ & $\begin{array}{c}0.0375 \\
(0.0229)\end{array}$ & $\begin{array}{c}0.0444^{*} \\
(0.0224)\end{array}$ \\
\hline
\end{tabular}

School x Cohort FE

Native language

FRPL eligible

No Yes

No No

No No

Maternal characteristics

No

No

Yes
Yes
No
No

Yes

Yes

Yes

Yes

Yes

Yes

Notes: The regressions include 33,880 unique late entering first generation Hispanic students, 49,839 unique early entering first generation Hispanic students, 88,116 unique second generation Hispanic students, 40,072 unique third generation Hispanic students, 4,326 unique late entering first generation Asian students, 4,837 unique early entering first generation Asian students, 9,245 unique second generation Asian students, 1,111 unique third generation Asian students, 342,297 unique third generation white students. Late entering students are defined as the students who entered the Florida public school system after the third grade. Standard errors clustered at the school by year level in parentheses, ${ }^{*} p<0.05,{ }^{* *} p<0.01,{ }^{* * *} p<0.001$. All models control for gender, age, special education status, and cohort fixed effects. 
Table A2 - Regression Adjusted Cross-Generational Differences in Hispanic and Asian Eighth Grade Disciplinary Incidents and Attendance, Compared to Third Generation White Students

\begin{tabular}{|c|c|c|c|c|c|c|}
\hline & & \multicolumn{5}{|c|}{ Disciplinary Incidents } \\
\hline & & $(1)$ & $(2)$ & (3) & (4) & $(5)$ \\
\hline \multicolumn{7}{|l|}{ Hispanics - } \\
\hline & Late Entering First Gen. & -0.000908 & $0.0111^{* * *}$ & 0.00134 & $-0.0243^{* * *}$ & \\
\hline & & $(0.00316)$ & $(0.00259)$ & $(0.00301)$ & $(0.00302)$ & \\
\hline & Early Entering First Gen. & -0.00494 & $0.0191^{* * *}$ & $0.00923^{* * *}$ & $-0.0121^{* * *}$ & \\
\hline & & $(0.00294)$ & $(0.00227)$ & $(0.00280)$ & $(0.00281)$ & \\
\hline & Second Generation & 0.000441 & $0.0287^{* * *}$ & $0.0202^{* * *}$ & 0.00116 & $-0.00939^{* * *}$ \\
\hline & & $(0.00275)$ & $(0.00195)$ & $(0.00232)$ & $(0.00232)$ & $(0.00254)$ \\
\hline & Third Generation & $0.0403^{* * *}$ & $0.0565^{* * *}$ & $0.0519^{* * *}$ & $0.0369^{* * *}$ & $0.0225^{* * *}$ \\
\hline & & $(0.00305)$ & $(0.00242)$ & $(0.00251)$ & $(0.00248)$ & $(0.00252)$ \\
\hline \multicolumn{7}{|l|}{ Asians - } \\
\hline & Late Entering First Gen. & $-0.114^{* * *}$ & $-0.110^{* * *}$ & $-0.118^{* * *}$ & $-0.123^{* * *}$ & \\
\hline & & $(0.00375)$ & $(0.00396)$ & $(0.00421)$ & $(0.00424)$ & \\
\hline & Early Entering First Gen. & $-0.0979^{* * *}$ & $-0.0805^{* * *}$ & $-0.0876^{* * *}$ & $-0.0887^{* * *}$ & \\
\hline & & $(0.00401)$ & $(0.00411)$ & $(0.00433)$ & $(0.00432)$ & \\
\hline & Second Generation & $-0.0926^{* * *}$ & $-0.0791^{* * *}$ & $-0.0852^{* * *}$ & $-0.0866^{* * *}$ & $-0.0780^{* * *}$ \\
\hline & & $(0.00324)$ & $(0.00325)$ & $(0.00345)$ & $(0.00346)$ & $(0.00357)$ \\
\hline & Third Generation & $-0.0352^{* * *}$ & $-0.0215^{*}$ & $-0.0223^{*}$ & $-0.0271^{* *}$ & $-0.0316^{* *}$ \\
\hline & & $(0.0103)$ & $(0.0102)$ & $(0.0103)$ & $(0.0103)$ & $(0.0104)$ \\
\hline & & & & Absent Days & & \\
\hline \\
\hline & Late Entering First Gen. & $-0.00254^{* * *}$ & $-0.00477^{* * *}$ & $-0.00427^{* * *}$ & $-0.00917^{* * *}$ & \\
\hline & & $(0.000578)$ & $(0.000521)$ & $(0.000583)$ & $(0.000589)$ & \\
\hline & Early Entering First Gen. & $-0.0106^{* * *}$ & $-0.00973^{* * *}$ & $-0.00922^{* * *}$ & $-0.0133^{* * *}$ & \\
\hline & & $(0.000510)$ & $(0.000427)$ & $(0.000508)$ & $(0.000516)$ & \\
\hline & Second Generation & $-0.00856^{* * *}$ & $-0.00747^{* * *}$ & $-0.00704^{* * *}$ & $-0.0107^{* * *}$ & $-0.0136^{* * *}$ \\
\hline & & $(0.000523)$ & $(0.000386)$ & $(0.000432)$ & $(0.000441)$ & $(0.000476)$ \\
\hline & Third Generation & $0.00263^{* * *}$ & $0.00217^{* * *}$ & $0.00241^{* * *}$ & -0.000430 & $-0.00353^{* * *}$ \\
\hline & & $(0.000586)$ & $(0.000445)$ & $(0.000456)$ & $(0.000451)$ & $(0.000454)$ \\
\hline \multicolumn{7}{|l|}{ Asians - } \\
\hline & Late Enternng rirst Uen. & $\begin{array}{l}-0.0209 \\
(0.000915)\end{array}$ & $\begin{array}{l}-0.0200 \\
(0.000907)\end{array}$ & $(0.000940)$ & $(0.000948)$ & \\
\hline & Early Entering First Gen. & $-0.0284^{* * *}$ & $-0.0253^{* * *}$ & $-0.0249^{* * *}$ & $-0.0252^{* * *}$ & \\
\hline
\end{tabular}




$\begin{array}{clllll} & (0.000720) & (0.000714) & (0.000741) & (0.000743) & \\ \text { Second Generation } & -0.0286^{* * *} & -0.0265^{* * *} & -0.0263^{* * *} & -0.0265^{* * *} & -0.0249^{* * *} \\ & (0.000572) & (0.000573) & (0.000593) & (0.000589) & (0.000606) \\ \text { Third Generation } & -0.00920^{* * *} & -0.00635^{* *} & -0.00646^{* *} & -0.00741^{* * *} & -0.00801^{* * *} \\ & (0.00201) & (0.00198) & (0.00198) & (0.00197) & (0.00196)\end{array}$

\section{School x Cohort FE}

Native language

FRPL eligible

$\begin{array}{lll}\text { No } & \text { Yes } & \text { Yes } \\ \text { No } & \text { No } & \text { Yes } \\ \text { No } & \text { No } & \text { No } \\ \text { No } & \text { No } & \text { No }\end{array}$

$\begin{array}{ll}\text { Yes } & \text { Yes } \\ \text { Yes } & \text { Yes } \\ \text { No } & \text { Yes } \\ \text { No } & \text { No }\end{array}$

Yes

Yes

Yes

Yes

Maternal characteristics

Notes: The regressions include 41,069 unique late entering first generation Hispanic students, 51,605 unique early entering first generation Hispanic students,

90,847 unique second generation Hispanic students, 41,764 unique third generation Hispanic students, 5,367 unique late entering first generation Asian students, 4,981 unique early entering first generation Asian students, 9,450 unique second generation Asian students, 1,175 unique third generation Asian students,

342,297 unique third generation white students. Late entering students are defined as the students who entered the Florida public school system after the third grade. Standard errors clustered at the school by year level in parentheses, ${ }^{*} p<0.05,{ }^{* *} p<0.01,{ }^{* * *} p<0.001$. All models control for gender, age, special education status, and cohort fixed effects. 
Table A3 - Regression Adjusted Cross-Generational Differences in Hispanic and Asian High School Graduation and Advanced Course-Taking, Compared to Third Generation White Students

\begin{tabular}{|c|c|c|c|c|c|}
\hline & \multicolumn{5}{|c|}{ Graduated from High School } \\
\hline & (1) & (2) & $(3)$ & (4) & (5) \\
\hline \multicolumn{6}{|l|}{ Hispanics - } \\
\hline \multirow[t]{2}{*}{ Late Entering First Gen. } & $-0.189^{* * *}$ & $-0.186^{* * *}$ & $-0.168^{* * *}$ & $-0.144^{* * *}$ & \\
\hline & $(0.00761)$ & $(0.00590)$ & $(0.00654)$ & $(0.00644)$ & \\
\hline \multirow[t]{2}{*}{ Early Entering First Gen. } & -0.000362 & $-0.00887^{*}$ & $0.00924^{*}$ & $0.0284^{* * *}$ & \\
\hline & $(0.00523)$ & $(0.00402)$ & $(0.00458)$ & $(0.00455)$ & \\
\hline \multirow[t]{2}{*}{ Second Generation } & 0.00285 & -0.00452 & $0.0111^{* *}$ & $0.0283^{* * *}$ & $0.0398^{* * *}$ \\
\hline & $(0.00595)$ & $(0.00387)$ & $(0.00420)$ & $(0.00416)$ & $(0.00437)$ \\
\hline \multirow[t]{2}{*}{ Third Generation } & $-0.0325^{* * *}$ & $-0.0354^{* * *}$ & $-0.0267^{* * *}$ & $-0.0133^{* * *}$ & 0.00478 \\
\hline & $(0.00562)$ & $(0.00390)$ & $(0.00403)$ & $(0.00388)$ & $(0.00382)$ \\
\hline \multicolumn{6}{|l|}{ Asians - } \\
\hline \multirow[t]{2}{*}{ Late Entering First Gen. } & $-0.0457^{* * *}$ & $-0.0527^{* * *}$ & $-0.0377^{* * *}$ & $-0.0321^{* * *}$ & \\
\hline & $(0.00951)$ & $(0.00925)$ & $(0.00964)$ & $(0.00956)$ & \\
\hline \multirow[t]{2}{*}{ Early Entering First Gen. } & $0.0895^{* * *}$ & $0.0716^{* * *}$ & $0.0854^{* * *}$ & $0.0900^{* * *}$ & \\
\hline & $(0.00799)$ & $(0.00834)$ & $(0.00879)$ & $(0.00894)$ & \\
\hline \multirow[t]{2}{*}{ Second Generation } & $0.111^{* * *}$ & $0.0936^{* * *}$ & $0.104^{* * *}$ & $0.105^{* * *}$ & $0.0896^{* * *}$ \\
\hline & $(0.00545)$ & $(0.00578)$ & $(0.00598)$ & $(0.00585)$ & $(0.00576)$ \\
\hline \multirow[t]{3}{*}{ Third Generation } & 0.00423 & 0.00523 & 0.00732 & 0.00995 & 0.0153 \\
\hline & $(0.0186)$ & $(0.0168)$ & $(0.0167)$ & $(0.0165)$ & $(0.0163)$ \\
\hline & \multicolumn{5}{|c|}{ Took an Advanced Course Before High School Graduation } \\
\hline \multicolumn{6}{|c|}{ - } \\
\hline \multirow{2}{*}{ Late Entering First Gen. } & $-0.142^{* * *}$ & $-0.191^{* * *}$ & $-0.149^{* * *}$ & $-0.110^{* * *}$ & \\
\hline & $(0.0139)$ & $(0.0102)$ & $(0.0102)$ & $(0.00990)$ & \\
\hline \multirow[t]{2}{*}{ Early Entering First Gen. } & 0.0214 & $-0.0360^{* * *}$ & 0.00537 & $0.0361^{* * *}$ & \\
\hline & $(0.0121)$ & $(0.00728)$ & $(0.00810)$ & $(0.00784)$ & \\
\hline \multirow[t]{2}{*}{ Second Generation } & -0.0238 & $-0.0799^{* * *}$ & $-0.0446^{* * *}$ & $-0.0179^{* *}$ & -0.00762 \\
\hline & $(0.0138)$ & $(0.00650)$ & $(0.00703)$ & $(0.00677)$ & $(0.00674)$ \\
\hline \multirow[t]{2}{*}{ Third Generation } & $-0.0388^{* *}$ & $-0.0937^{* * *}$ & $-0.0748^{* * *}$ & $-0.0561^{* * *}$ & $-0.0396^{* * *}$ \\
\hline & $(0.0119)$ & $(0.00650)$ & $(0.00659)$ & $(0.00650)$ & $(0.00653)$ \\
\hline \multicolumn{6}{|l|}{ Asians - } \\
\hline \multirow[t]{2}{*}{ Late Entering First Gen. } & $0.239^{* * *}$ & $0.131^{* * *}$ & $0.165^{* * *}$ & $0.176^{* * *}$ & \\
\hline & $(0.0152)$ & $(0.0139)$ & $(0.0144)$ & $(0.0142)$ & \\
\hline
\end{tabular}




$\begin{array}{ccc}\text { Early Entering First Gen. } & 0.290^{* * *} & 0.176^{* * *} \\ & (0.0142) & (0.0133) \\ \text { Second Generation } & 0.280^{* * *} & 0.171^{* * *} \\ & (0.0112) & (0.0104) \\ \text { Third Generation } & 0.0794^{*} & 0.0228 \\ & (0.0312) & (0.0276)\end{array}$

$\begin{array}{ll}\text { No } & \text { Yes } \\ \text { No } & \text { No } \\ \text { No } & \text { No } \\ \text { No } & \text { No }\end{array}$

No

$\begin{array}{cc}0.208^{* * *} & 0.217^{* * *} \\ (0.0138) & (0.0140) \\ 0.196^{* * *} & 0.200^{* * *} \\ (0.0107) & (0.0106) \\ 0.0274 & 0.0302 \\ (0.0279) & (0.0275)\end{array}$

$0.184^{* * *}$

$(0.0105)$

0.0349

$(0.0264)$

$\begin{array}{lll}\text { Yes } & \text { Yes } & \text { Yes } \\ \text { Yes } & \text { Yes } & \text { Yes } \\ \text { No } & \text { Yes } & \text { Yes } \\ \text { No } & \text { No } & \text { Yes }\end{array}$

Maternal characteristics

Notes: High school graduation regressions include 15,943 unique late entering first generation Hispanic students, 20,467 unique early entering first generation Hispanic students, 36,260 unique second generation Hispanic students, 15,685 unique third generation Hispanic students, 1,810 unique late entering first generation Asian students, 1,806 unique early entering first generation Asian students, 3,728 unique second generation Asian students, 418 unique third generation Asian students, and 154,758 unique third generation white students. Advanced course-taking regressions include 7,883 unique late entering first generation Hispanic students, 10,914 unique early entering first generation Hispanic students, 20,362 unique second generation Hispanic students, 8,178 unique third generation Hispanic students, 1,170 unique late entering first generation Asian students, 1,261 unique early entering first generation Asian students, 2,862 unique second generation Asian students, 268 unique third generation Asian students, and 92,346 unique third generation white students. Late entering students are defined as the students who entered the Florida public school system after the third grade. Standard errors clustered at the school by year level in parentheses, ${ }^{*} p<0.05,{ }^{* *} p<0.01,{ }^{* * *} p<0.001$. All models control for gender, age of the student when he/she enters the ninth grade for the first time, special education status, and cohort fixed-effects. 


\section{APPENDIX B}

Figure B1 - Cross-Generational Differences in Eighth Grade Reading Scores among Hispanic Students, Compared to Third Generation Whites, by Grade of Entry into the School System for the First Generation Immigrants, by Country of Origin

(I) Puerto Rico

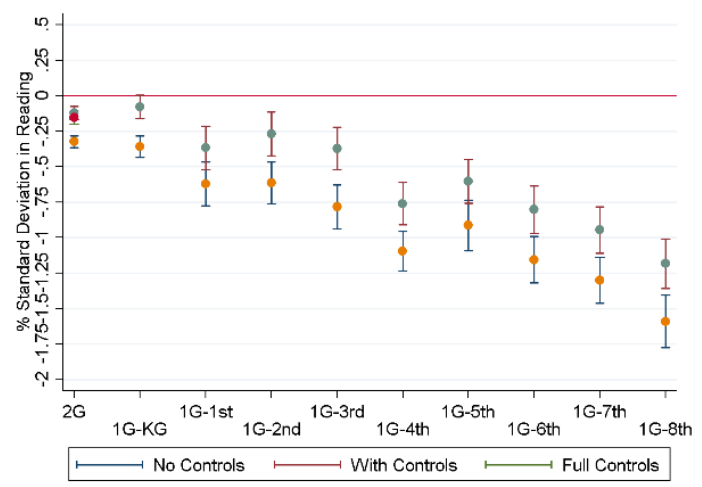

(III) Mexico

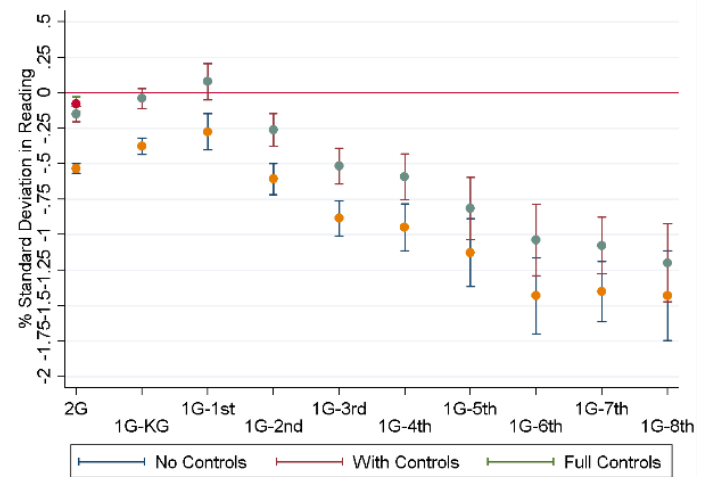

(II) Cuba

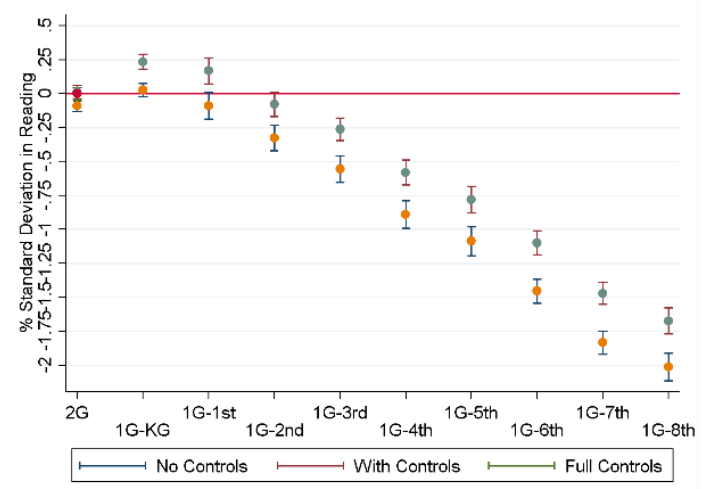

(IV) Other

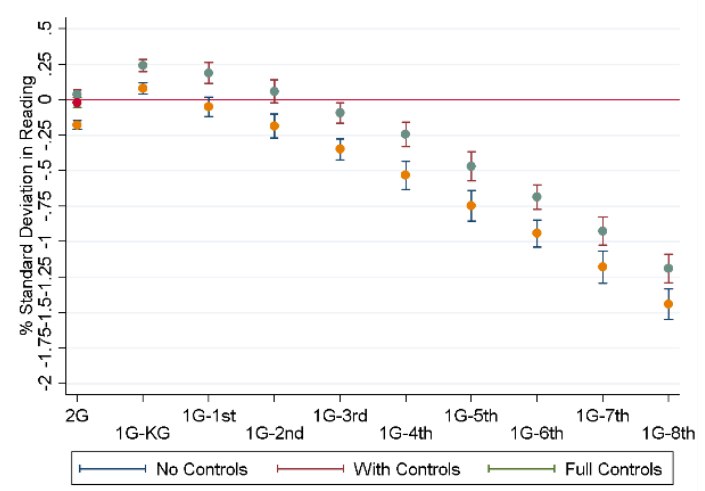

Notes: The "no controls", "with controls", and "full controls" specifications are obtained using models with only disability, gender, age controls, and cohort fixed-effects (no controls), controls for school by cohort fixed effects, language spoken at home, and school lunch eligibility (with controls), and also maternal characteristics (full controls). The first generation indicators replaced by a series of first generation indicators based on grade of entry. Standard errors clustered at the school by year level. Capped spikes represent the 95 percent confidence interval for each coefficient. Regressions include 1,647 unique first generation Puerto Rican immigrants, 2,374 unique second generation Puerto Rican immigrants, 6,464 unique first generation Cuban immigrants, 5,543 unique second generation Cuban immigrants, 2,283 unique first generation Mexican immigrants, 4,239 unique second generation Mexican immigrants, 8,894 unique first generation immigrants from other countries, 9,842 unique second generation immigrants from other countries. 
Figure B2 - Cross-Generational Differences in Eighth Grade Math Scores among Hispanic Students, Compared to Third Generation Whites, by Grade of Entry into the School System for the First Generation Immigrants, by Country of Origin
(I) Puerto Rico
(II) Cuba
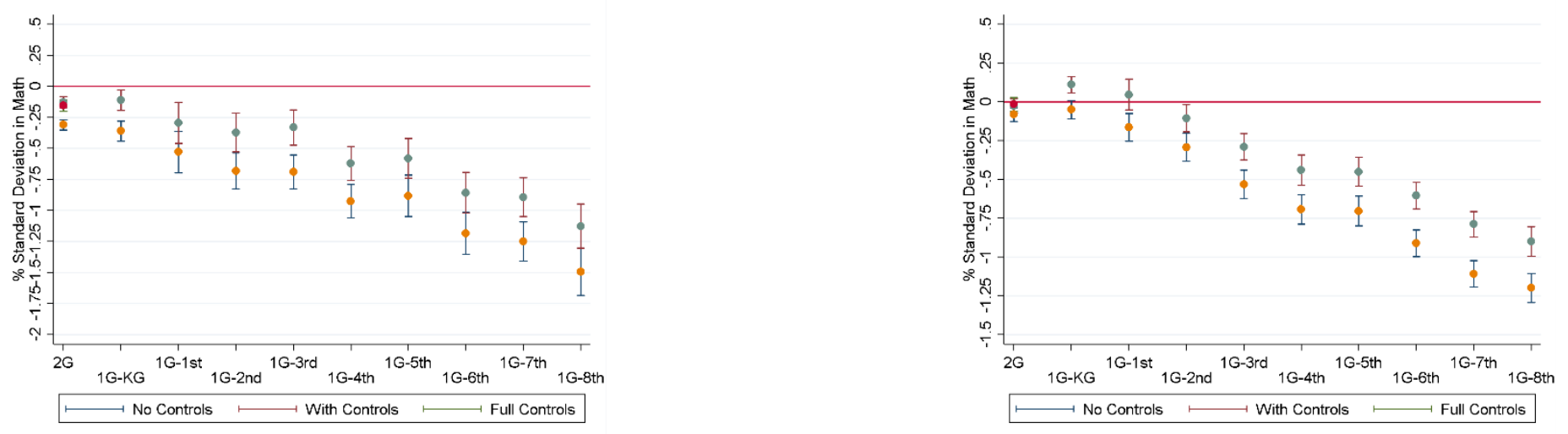

(III) Mexico
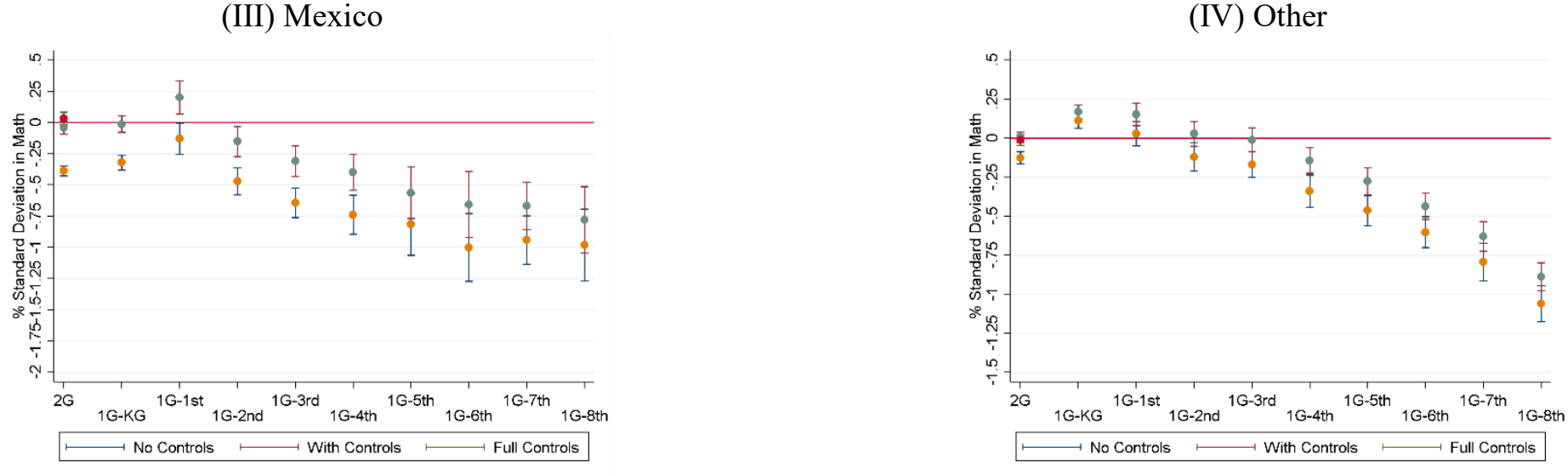

Notes: The "no controls", "with controls", and "full controls" specifications are obtained using models with only disability, gender, age controls, and cohort fixed-effects (no controls), controls for school by cohort fixed effects, language spoken at home, and school lunch eligibility (with controls), and also maternal characteristics (full controls). The first generation indicators replaced by a series of first generation indicators based on grade of entry. Standard errors clustered at the school by year level. Capped spikes represent the 95 percent confidence interval for each coefficient. Regressions include 1,647 unique first generation Puerto Rican immigrants, 2,374 unique second generation Puerto Rican immigrants, 6,464 unique first generation Cuban immigrants, 5,543 unique second generation Cuban immigrants, 2,283 unique first generation Mexican immigrants, 4,239 unique second generation Mexican immigrants, 8,894 unique first generation immigrants from other countries, 9,842 unique second generation immigrants from other countries. 
Figure B3 - Cross-Generational Differences in Eighth Grade Reading Scores among Hispanic Students, Compared to Third Generation Whites, by Grade of Entry into the School System for the First Generation Immigrants, by Country of Origin

(I) Philippines

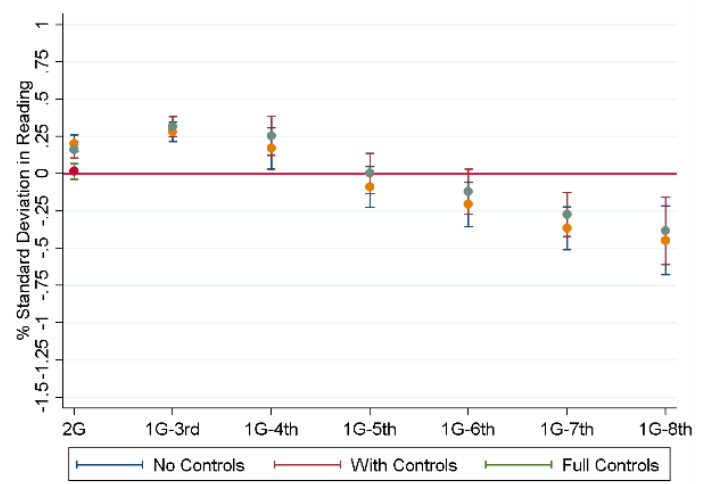

(III) Japan

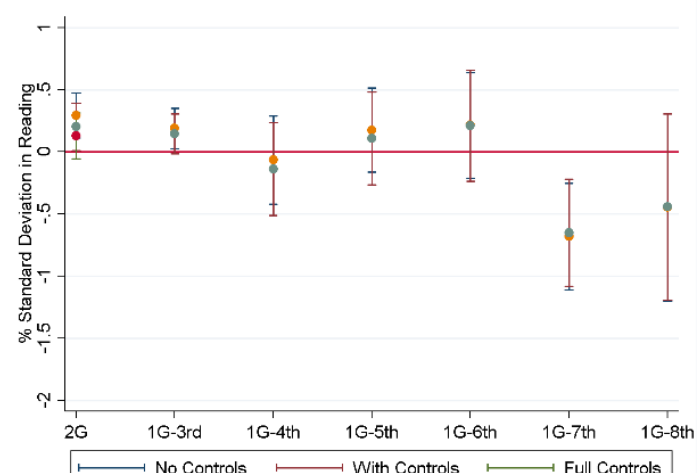

(II) China

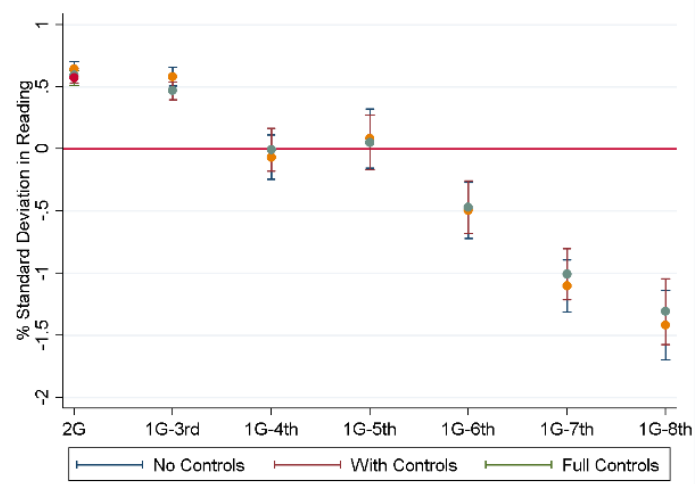

(IV) Other

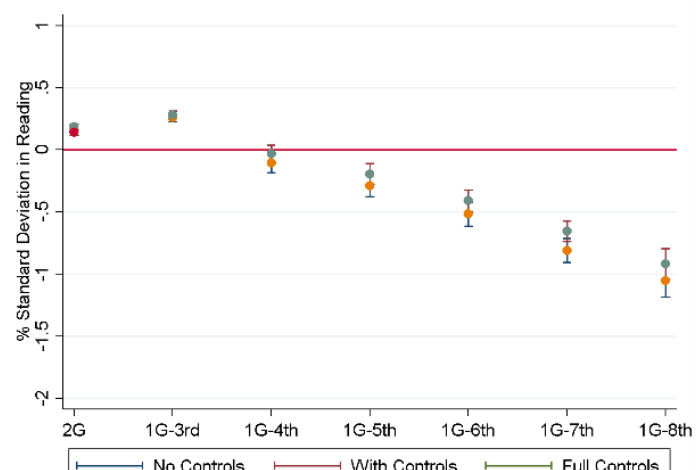

Notes: The "no controls", "with controls", and "full controls" specifications are obtained using models with only disability, gender, age controls, and cohort fixed-effects (no controls), controls for school by cohort fixed effects, language spoken at home, and school lunch eligibility (with controls), and also maternal characteristics (full controls). The first generation indicators replaced by a series of first generation indicators based on grade of entry where "1G-3 $3^{\text {rd }}$ indicates entry during or before the third grade. Standard errors clustered at the school by year level. Capped spikes represent the 95 percent confidence interval for each coefficient. Regressions include 1,437 unique first generation Filipino immigrants, 1,069 unique second generation Filipino immigrants, 1,192 unique first generation Chinese immigrants, 984 unique second generation Chinese immigrants, 216 unique first generation Japanese immigrants, 70 unique second generation Japanese immigrants, 6,534 unique first generation immigrants from other countries, 7,192 unique second generation immigrants from other countries. 
Figure B4 - Cross-Generational Differences in Eighth Grade Math Scores among Hispanic Students, Compared to Third Generation Whites, by Grade of Entry into the School System for the First Generation Immigrants, by Country of Origin

(I) Philippines

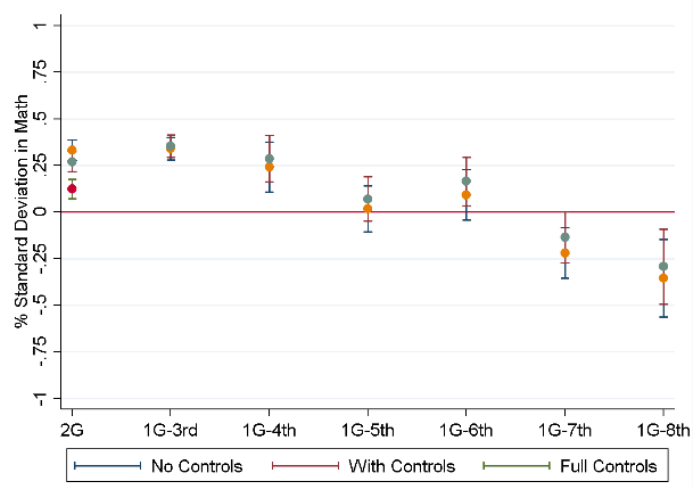

(III) Japan

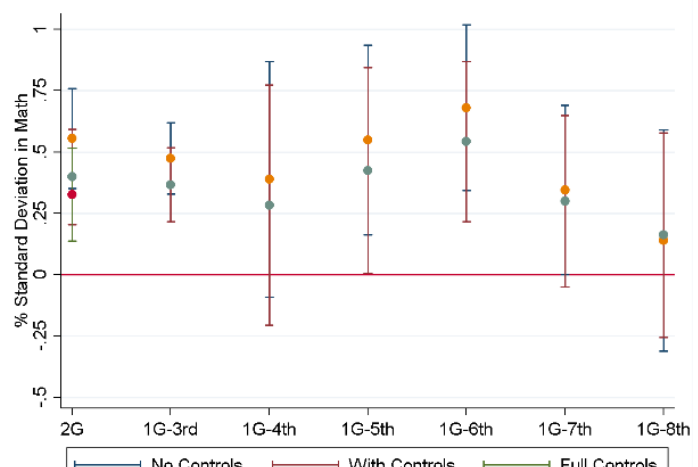

(II) China

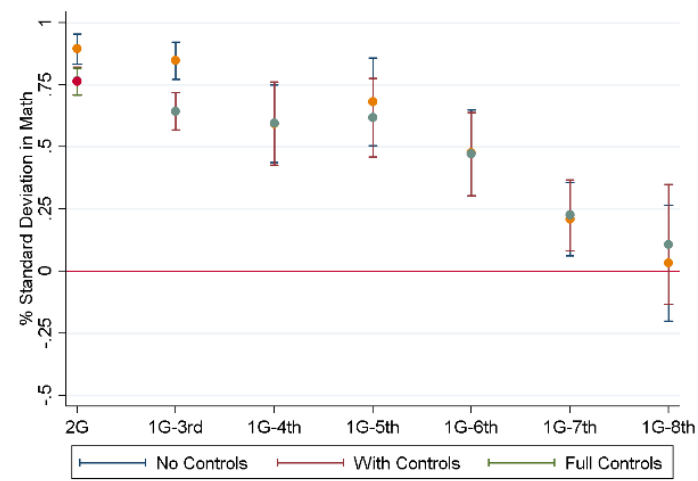

(IV) Other

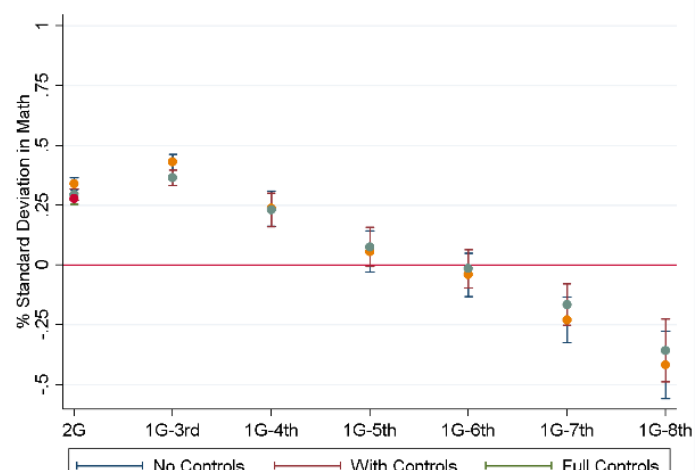

Notes: The "no controls", "with controls", and "full controls" specifications are obtained using models with only disability, gender, age controls, and cohort fixed-effects (no controls), controls for school by cohort fixed effects, language spoken at home, and school lunch eligibility (with controls), and also maternal characteristics (full controls). The first generation indicators replaced by a series of first generation indicators based on grade of entry where "1G-3 $3^{\text {rd }}$ indicates entry during or before the third grade. Standard errors clustered at the school by year level. Capped spikes represent the 95 percent confidence interval for each coefficient. Regressions include 1,437 unique first generation Filipino immigrants, 1,069 unique second generation Filipino immigrants, 1,192 unique first generation Chinese immigrants, 984 unique second generation Chinese immigrants, 216 unique first generation Japanese immigrants, 70 unique second generation Japanese immigrants, 6,534 unique first generation immigrants from other countries, 7,192 unique second generation immigrants from other countries. 


\section{CROSS-GENERATIONAL DIFFERENCES IN EDUCATIONAL OUTCOMES IN THE SECOND GREAT WAVE OF IMMIGRATION APPENDIX FOR ONLINE PUBLICATION}

Online Figure 1 - Cross-Generational Differences in Eighth Grade Test Scores among Hispanic and Asian Students, Compared to Third Generation Whites, by Grade of Entry into the School System for the First Generation Immigrants, including Students Born in Another State

(I) Reading - Hispanic

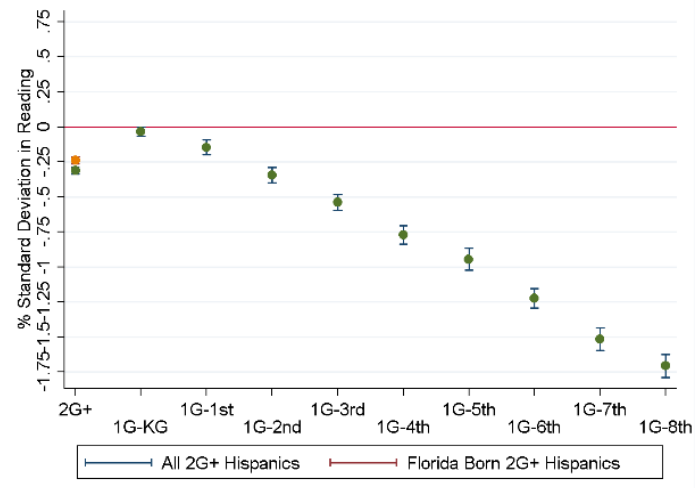

(III) Math - Hispanic

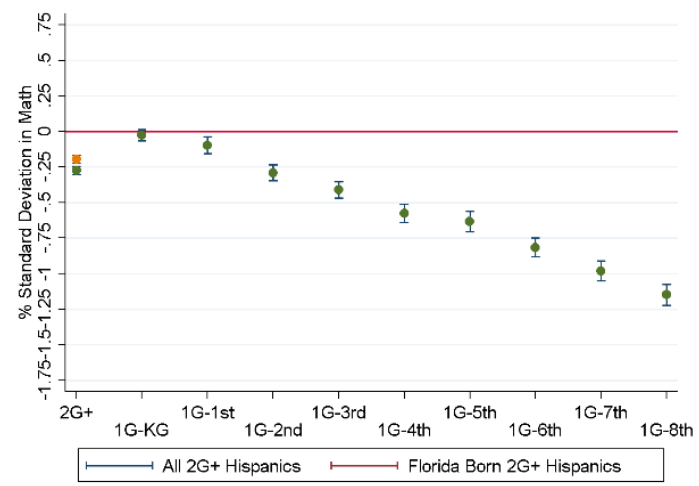

(II) Reading - Asian

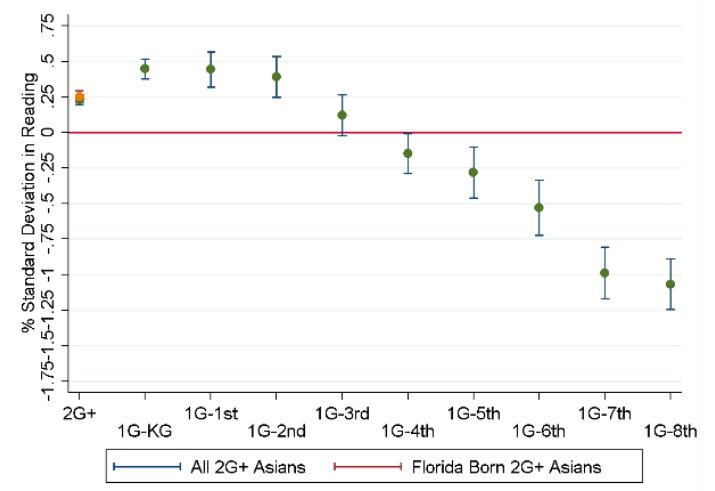

(IV) Math - Asian

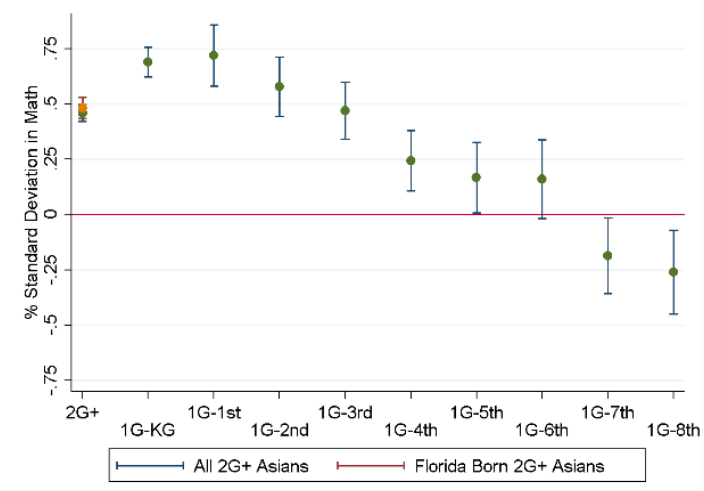

Notes: The estimated cross-generational differences are obtained using models with only disability, gender, age controls, and cohort fixed-effects, estimated separately using all second and higher generation students and using only Florida-born second and higher generation students. The first generation indicators replaced by a series of first generation indicators based on grade of entry. Standard errors clustered at the school by year level. Capped spikes represent the 95 percent confidence interval for each coefficient. Regressions include 19,286 unique first generation Hispanic immigrants, 2,375 unique first generation Asian immigrants; 51,892 unique second or higher generation Hispanic immigrants, 5,615 unique second or higher generation Asian immigrants including the native students born in another state; 32,531 unique second or higher generation Hispanic immigrants, 2,865 unique second or higher generation Asian immigrants excluding the native students born in another state. 
Online Figure 2 - Cross-Generational Differences in Raw Trends in Student Test Scores over Grades among Hispanic and Asian Students, Compared to Third Generation Whites in grades 3 through 8, Conditional on Continuous Enrollment

\section{(I) Reading - Hispanic}

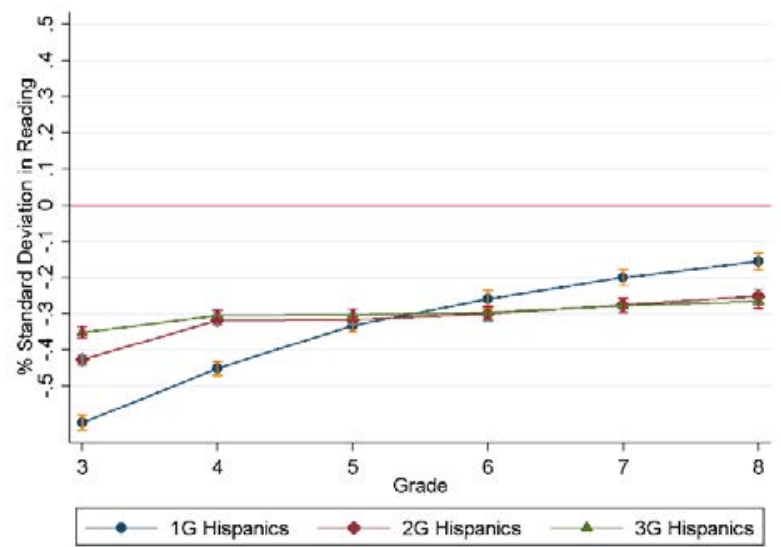

(III) Math - Hispanic

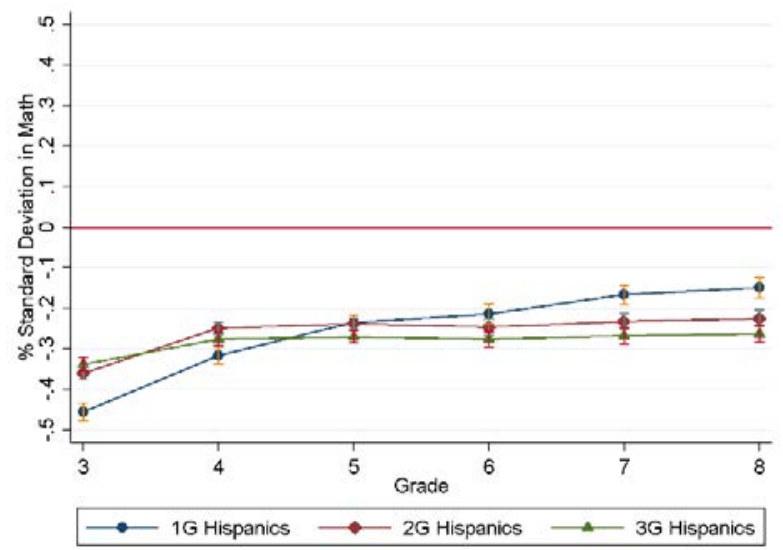

(II) Reading - Asian

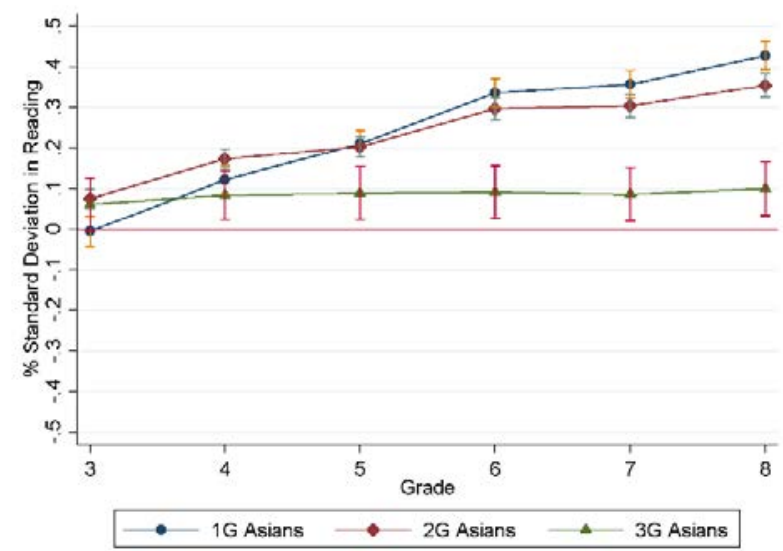

(IV) Math - Asian

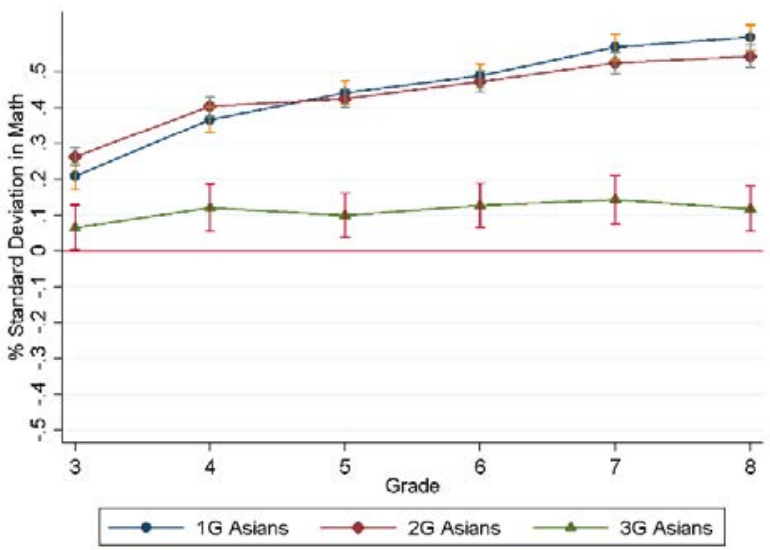

Notes: The estimated cross-generational differences among Asian, Hispanic, compared to the third generation white students are obtained without any additional covariates, estimated separately for each given grade. Standard errors clustered at the school by year level. Capped spikes represent the 95 percent confidence interval for each estimated coefficient. The regressions include 34,325 unique early entering first generation Hispanic students, 61,439 unique second generation Hispanic students, 27,018 unique third generation Hispanic students, 3,321 unique early entering first generation Asian students, 6,307 unique second generation Asian students, 709 unique third generation Asian students, and 218,830 unique third generation white students. 
Online Figure 3 - Cross-Generational Differences in Raw Trends in Student Disciplinary Incidents and Absences over Grades among Hispanic and Asian Students, Compared to Third Generation Whites in grades 3 through 8, Conditional on Continuous Enrollment

(I) Disciplinary Incidents - Hispanic

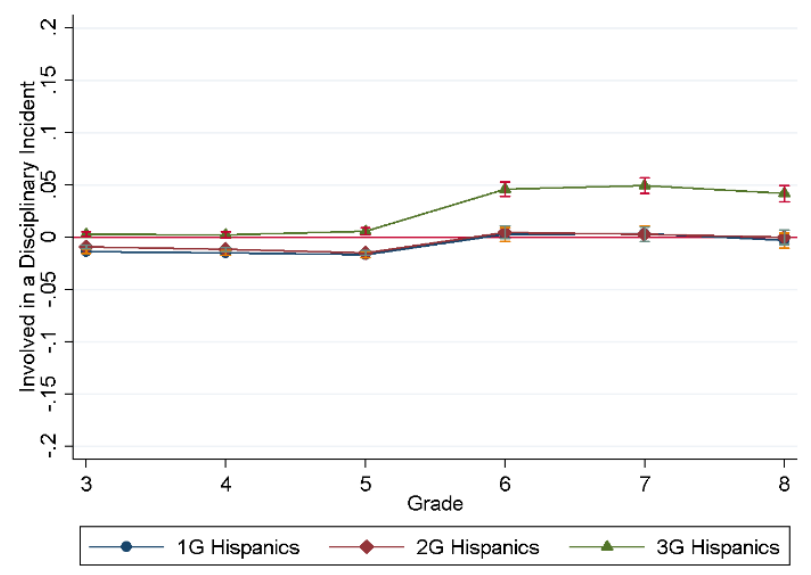

(III) \% Absent Days - Hispanic

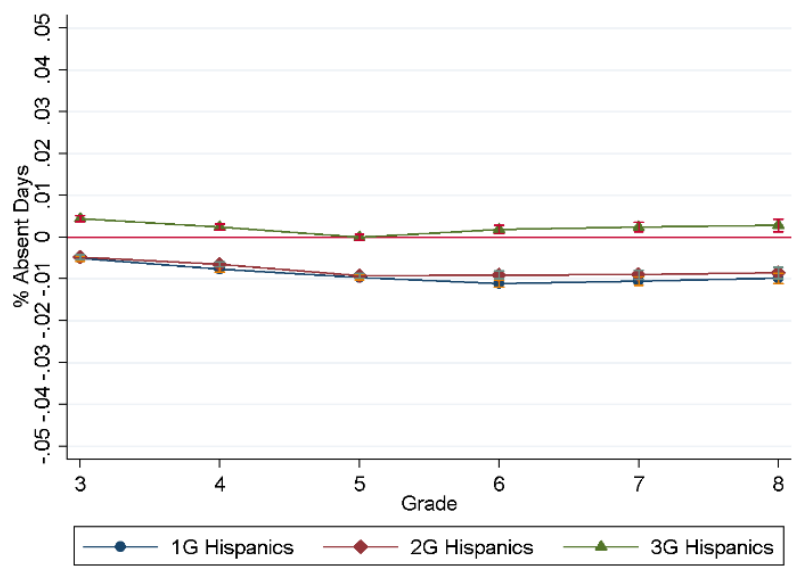

(II) Disciplinary Incidents - Asian

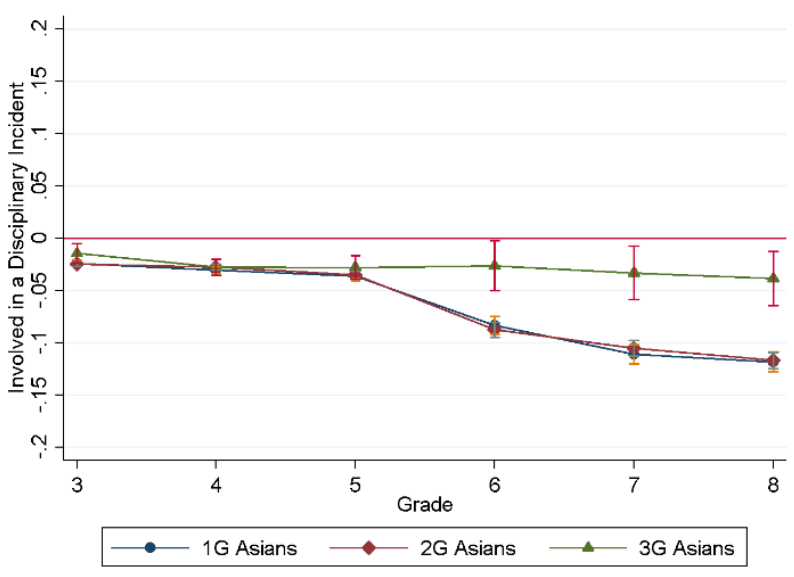

(IV) \% Absent Days - Asian

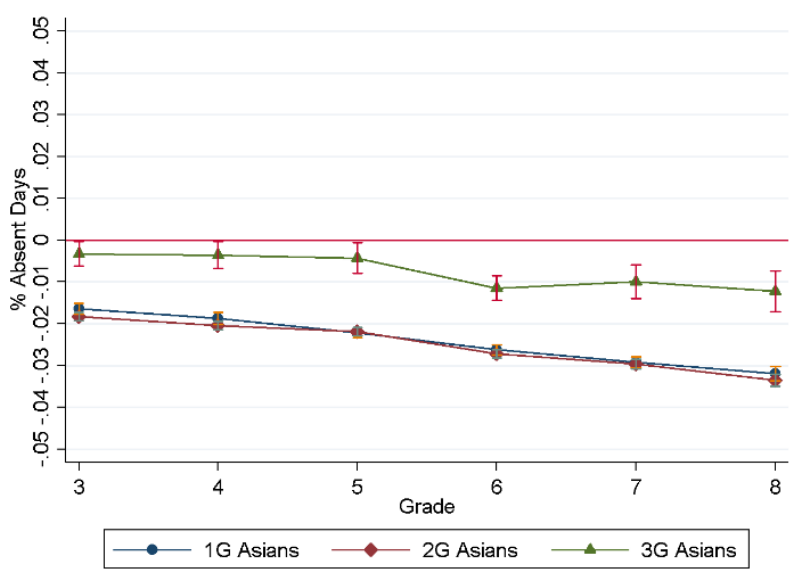

Notes: The estimated cross-generational differences among Asian, Hispanic, compared to the third generation white students are obtained without any additional covariates, estimated separately for each given grade. Standard errors clustered at the school by year level. Capped spikes represent the 95 percent confidence interval for each estimated coefficient. The regressions include 37,402 unique early entering first generation Hispanic students, 63,251 unique second generation Hispanic students, 28,406 unique third generation Hispanic students, 3,694 unique early entering first generation Asian students, 6,457 unique second generation Asian students, 754 unique third generation Asian students, and 234,095 unique third generation white students. 
Online Figure 4 - Cross-Generational Differences in Eighth Grade Test Scores, Disciplinary Incidents, and Absences among Hispanic Students, Compared to Third Generation Whites, by Grade of Entry into the School System for the First Generation Immigrants, Excluding Students of Cuban or Puerto Rican Origin

\section{(I) Reading}

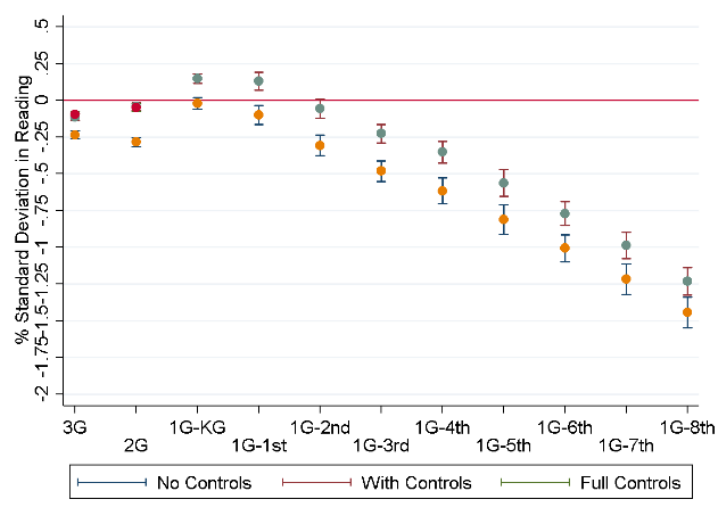

(III) Disciplinary Incidents

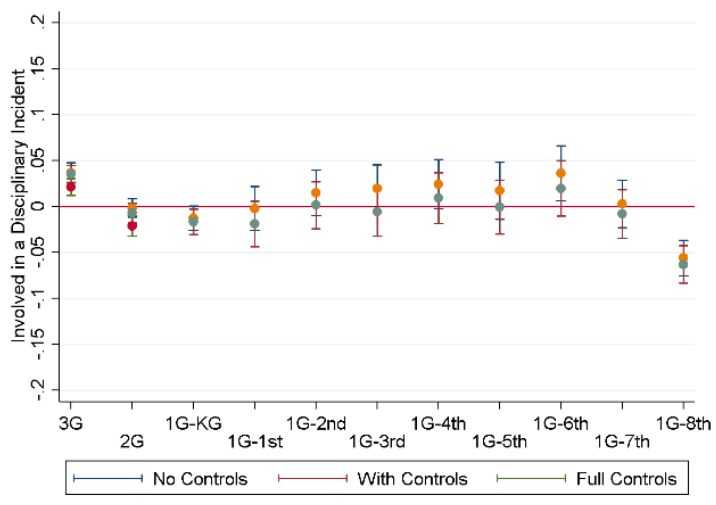

(II) Math

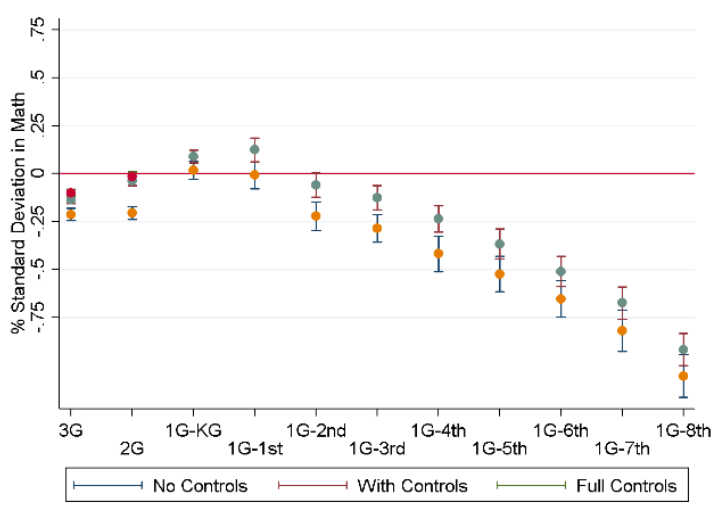

(IV) \% Absent Days

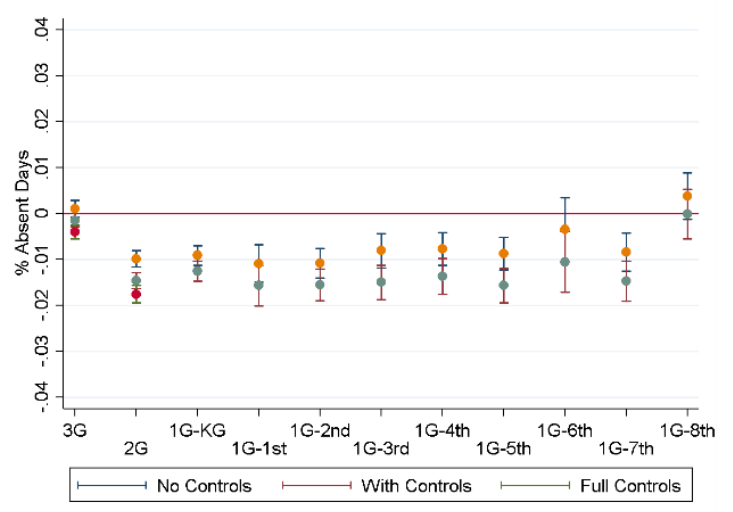

Notes: The "no controls", "with controls", and "full controls" specifications are obtained using models with only disability, gender, age controls, and cohort fixed-effects (no controls), controls for school by cohort fixed effects, English language spoken at home, and school lunch eligibility (with controls), and also maternal characteristics (full controls). The first generation indicators replaced by a series of first generation indicators based on grade of entry. Standard errors clustered at the school by year level. Capped spikes represent the 95 percent confidence interval for each coefficient. The regressions in the top panel include 11,176 unique first generation Hispanic students, 14,081 unique second generation Hispanic students, 10,533 unique third generation Hispanic students, and 76,664 unique third generation white students for the top panel; 11,965 unique first generation Hispanic students, 14,367 unique second generation Hispanic students, 10,874 unique third generation Hispanic students, and 76,664 unique third generation white students for the top panel. 
Online Figure 5 - Cross-Generational Differences in Eighth Grade Test Scores Compared to Third Generation Whites, by Grade of Entry into the School System for the First Generation Immigrants, Student Racial/Ethnic Identification versus Mother Racial/Ethnic Identification, Excluding Students of Cuban or Puerto Rican Origin

(I) Reading

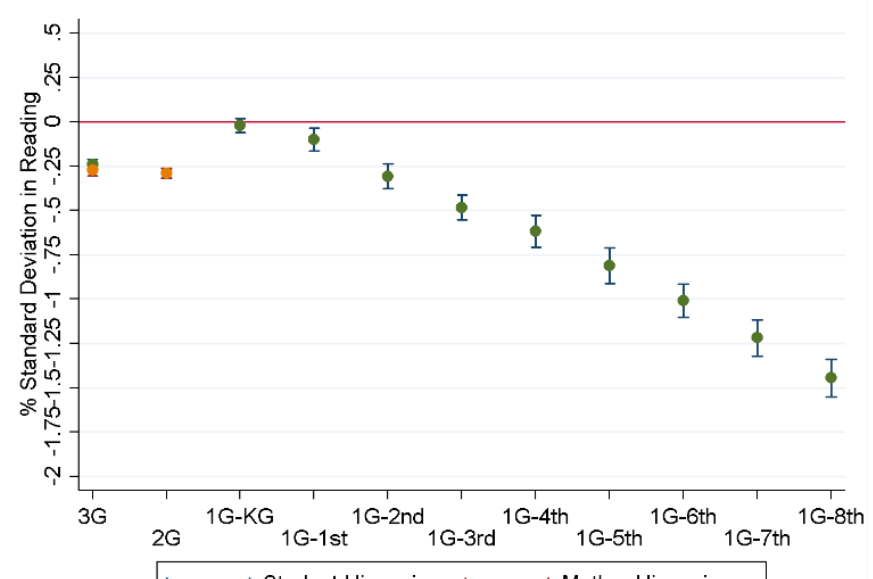

(II) Math

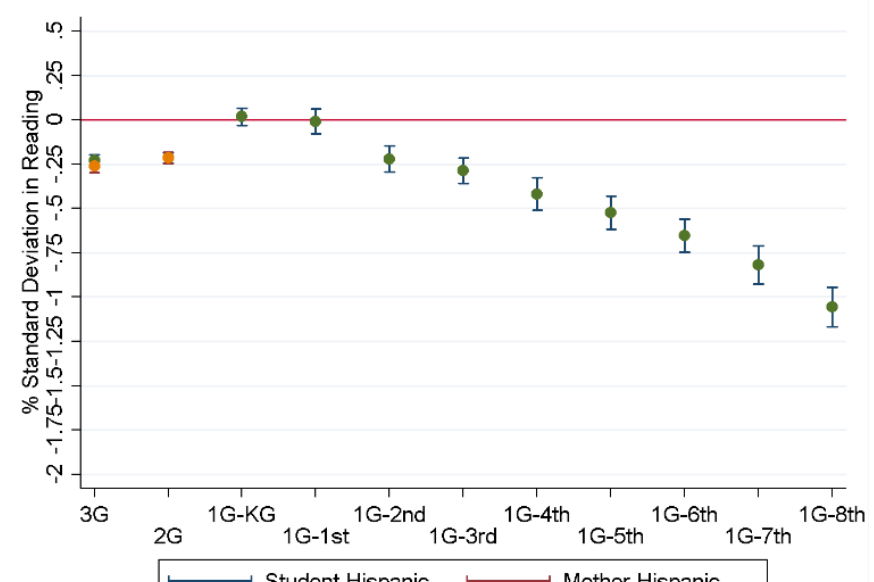

Notes: The estimates are obtained using the model that controls for disability, gender, age controls, and cohort fixed-effects. "Student Hispanic" specification use the self-reported race/ethnicity whereas "Mother Hispanic" specification use the self-reported race/ethnicity of the mother to identify second and third generation Hispanic immigrants. Standard errors clustered at the school by year level. Capped spikes represent the 95 percent confidence interval for each coefficient. The regressions include 11,176 unique first generation Hispanic students, 19,788 unique second generation students with Hispanic mothers, 9,823 unique third generation students with Hispanic mothers, 14,081 unique second generation Hispanic students, 10,533 unique third generation Hispanic students, and 79,052 unique third generation white students with non-Hispanic and non-Asian mothers. 
Online Figure 6 - Cross-Generational Differences in High School Graduation and Course-Taking among Hispanic Students, Compared to Third Generation Whites, by Grade of Entry into the School System for the First Generation Immigrants, Excluding Students of Cuban or Puerto Rican Origin

(I) High School Graduation

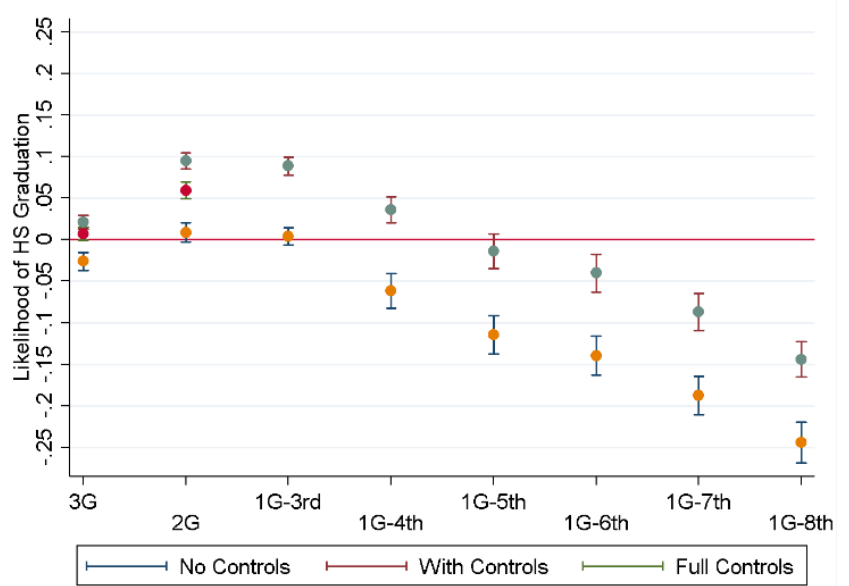

(II) Advanced Course-Taking

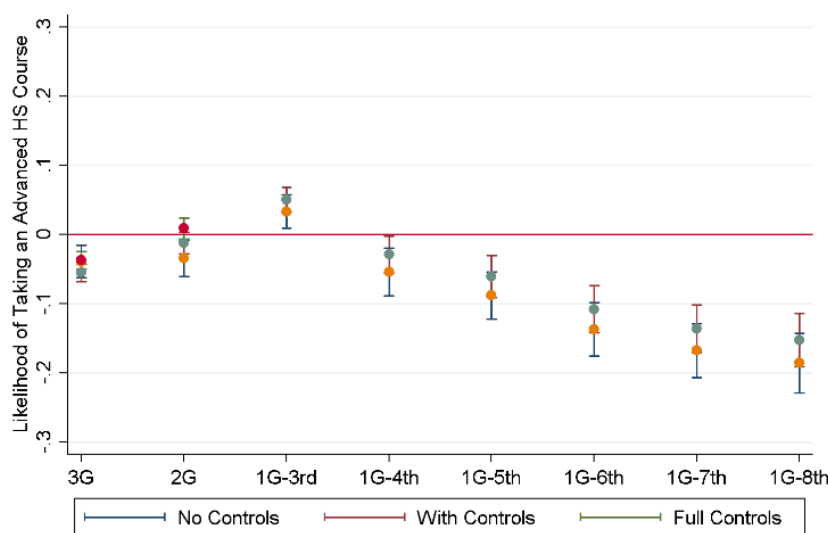

Notes: The "no controls", "with controls", and "full controls" specifications are obtained using models with only disability, gender, age controls, and cohort fixed-effects (no controls), controls for school by cohort fixed effects, English language spoken at home, and school lunch eligibility (with controls), and also maternal characteristics (full controls). The first generation indicators replaced by a series of first generation indicators based on grade of entry. Standard errors clustered at the school by year level. Capped spikes represent the 95 percent confidence interval for each coefficient. High school graduation regressions include 24,866 unique first generation Hispanic students, 23,195 unique second generation Hispanic students, 15,685 unique third generation Hispanic students, and 154,758 unique third generation white students. Advanced course-taking regressions include 13,238 unique first generation Hispanic students, 12,898 unique second generation Hispanic students, 8,297 unique third generation Hispanic students, and 93,641 unique third generation white students. 
Online Figure 7 - Cross-Generational Regression-Adjusted Trends in Student Test Scores over Grades among Hispanic Students, Compared to Third Generation Whites in grades 3 through 8, Conditional on Continuous Enrollment, Excluding Students of Cuban or Puerto Rican Origin

(I) Reading

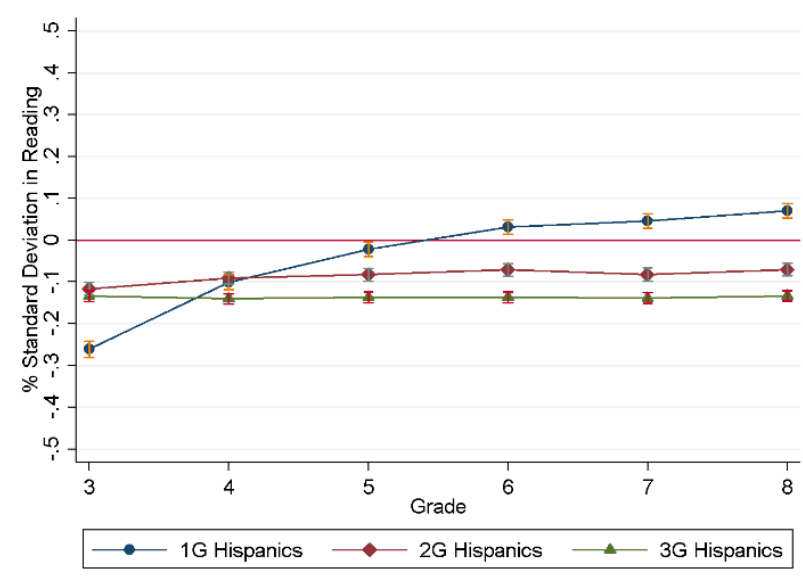

(III) Disciplinary Incidents

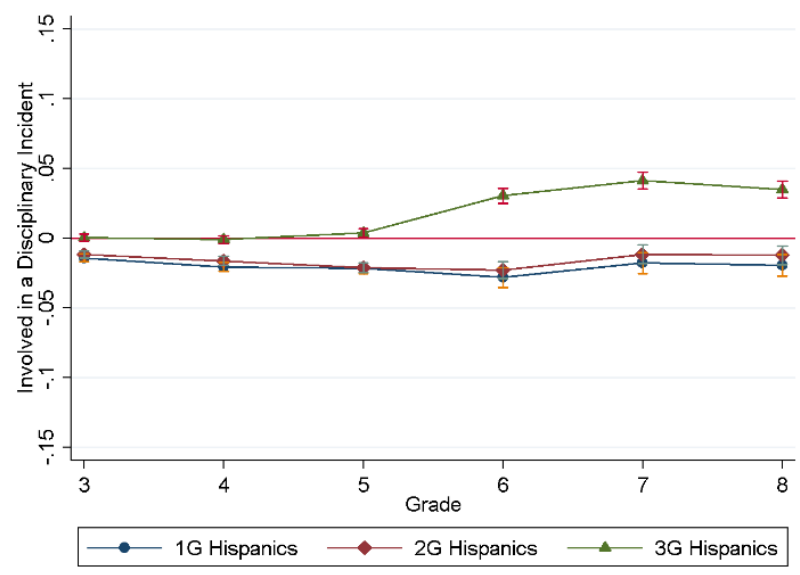

(II) Math

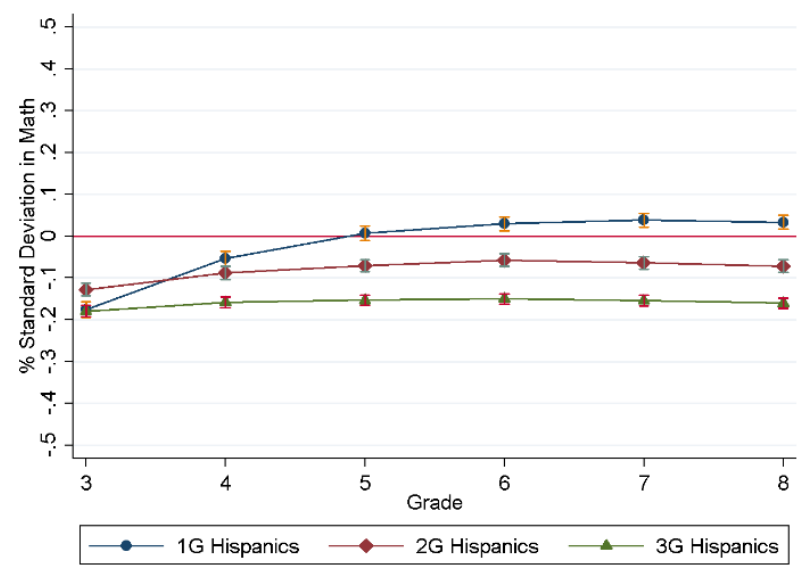

(IV) \% Absent Days

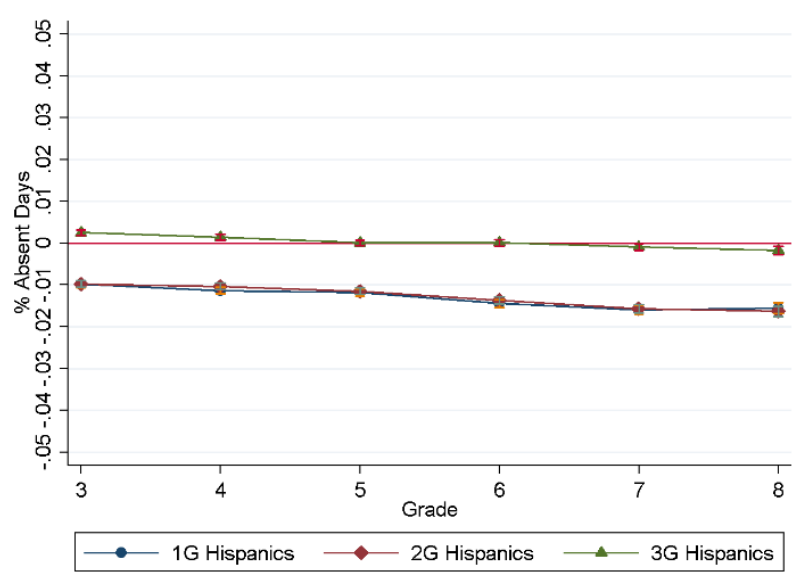

Notes: The estimated cross-generational differences among Hispanic students compared to the third generation white students are obtained using the covariates given in column (IV), Table A1, estimated separately for each given grade. Standard errors clustered at the school by year level. Capped spikes represent the 95 percent confidence interval for each estimated coefficient. The regressions include 23,694 unique early entering first generation Hispanic students, 39,922 unique second generation Hispanic students, 27,018 unique third generation Hispanic students, and 218,830 unique third generation white students. 
Online Table 1 - Regression Adjusted Cross-Generational Differences in Hispanic Test Scores, Compared to Third Generation White Students in Grades 3 through 8, Excluding Cuban and Puerto Rican Students

\begin{tabular}{|c|c|c|c|c|c|}
\hline & \multicolumn{5}{|c|}{ Reading Scores } \\
\hline & (1) & $(2)$ & (3) & (4) & $(5)$ \\
\hline \multirow[t]{2}{*}{ Late Entering First Gen. } & $-0.979^{* * *}$ & $-0.933^{* * *}$ & $-0.776^{* * *}$ & $-0.692^{* * *}$ & \\
\hline & $(0.0101)$ & $(0.00720)$ & $(0.00731)$ & $(0.00721)$ & \\
\hline \multirow[t]{2}{*}{ Early Entering First Gen. } & $-0.319^{* * *}$ & $-0.294^{* * *}$ & $-0.135^{* * *}$ & $-0.0647^{* * *}$ & \\
\hline & $(0.00542)$ & $(0.00311)$ & $(0.00335)$ & $(0.00326)$ & \\
\hline \multirow[t]{2}{*}{ Second Generation } & $-0.369^{* * *}$ & $-0.287^{* * *}$ & $-0.145^{* * *}$ & $-0.0732^{* * *}$ & $-0.0666^{* * *}$ \\
\hline & $(0.00363)$ & $(0.00223)$ & $(0.00250)$ & $(0.00240)$ & $(0.00232)$ \\
\hline \multirow[t]{3}{*}{ Third Generation } & $-0.293^{* * *}$ & $-0.253^{* * *}$ & $-0.179^{* * *}$ & $-0.128^{* * *}$ & $-0.109^{* * *}$ \\
\hline & $(0.00321)$ & $(0.00203)$ & $(0.00208)$ & $(0.00198)$ & $(0.00189)$ \\
\hline & \multicolumn{5}{|c|}{ Math Scores } \\
\hline \multirow[t]{2}{*}{ Late Entering First Gen. } & $-0.692^{* * *}$ & $-0.679^{* * *}$ & $-0.560^{* * *}$ & $-0.480^{* * *}$ & \\
\hline & $(0.00977)$ & $(0.00615)$ & $(0.00631)$ & $(0.00621)$ & \\
\hline \multirow[t]{2}{*}{ Early Entering First Gen. } & $-0.193^{* * *}$ & $-0.210^{* * *}$ & $-0.0896^{* * *}$ & $-0.0215^{* * *}$ & \\
\hline & $(0.00540)$ & $(0.00277)$ & $(0.00309)$ & $(0.00300)$ & \\
\hline \multirow[t]{2}{*}{ Second Generation } & $-0.268^{* * *}$ & $-0.226^{* * *}$ & $-0.118^{* * *}$ & $-0.0487^{* * *}$ & $-0.0289^{* * *}$ \\
\hline & $(0.00377)$ & $(0.00209)$ & $(0.00242)$ & $(0.00235)$ & $(0.00235)$ \\
\hline \multirow[t]{2}{*}{ Third Generation } & $-0.265^{* * *}$ & $-0.251^{* * *}$ & $-0.195^{* * *}$ & $-0.146^{* * *}$ & $-0.117^{* * *}$ \\
\hline & $(0.00330)$ & $(0.00194)$ & $(0.00203)$ & $(0.00194)$ & $(0.00188)$ \\
\hline School-Year FE & No & Yes & Yes & Yes & Yes \\
\hline Native language & No & No & Yes & Yes & Yes \\
\hline FRPL eligible & No & No & No & Yes & Yes \\
\hline Maternal characteristics & No & No & No & No & Yes \\
\hline
\end{tabular}


Online Table 2 - Regression Adjusted Cross-Generational Differences in Hispanic Disciplinary Incidents and Attendance, Compared to Third Generation White Students in Grades KG through 8, Excluding Cuban and Puerto Rican Students

\begin{tabular}{|c|c|c|c|c|c|}
\hline & \multicolumn{5}{|c|}{ Disciplinary Incidents } \\
\hline & (1) & $(2)$ & (3) & (4) & $(5)$ \\
\hline \multicolumn{6}{|l|}{ Hispanics - } \\
\hline \multirow[t]{2}{*}{ Late Entering First Gen. } & $-0.0188^{* * *}$ & $-0.0160^{* * *}$ & $-0.0193^{* * *}$ & $-0.0307^{* * *}$ & \\
\hline & $(0.00159)$ & $(0.00112)$ & $(0.00117)$ & $(0.00116)$ & \\
\hline \multirow[t]{2}{*}{ Early Entering First Gen. } & $-0.0157^{* * *}$ & $-0.00880^{* * *}$ & $-0.0122^{* * *}$ & $-0.0223^{* * *}$ & \\
\hline & $(0.000777)$ & $(0.000535)$ & $(0.000624)$ & $(0.000632)$ & \\
\hline \multirow[t]{2}{*}{ Second Generation } & $-0.00895^{* * *}$ & $-0.00317^{* * *}$ & $-0.00622^{* * *}$ & $-0.0169^{* * *}$ & $-0.0209^{* * *}$ \\
\hline & $(0.000635)$ & $(0.000466)$ & $(0.000535)$ & $(0.000535)$ & $(0.000557)$ \\
\hline \multirow[t]{3}{*}{ Third Generation } & $0.0132^{* * *}$ & $0.0183^{* * *}$ & $0.0167^{* * *}$ & $0.00900^{* * *}$ & $0.00405^{* * *}$ \\
\hline & $(0.000704)$ & $(0.000506)$ & $(0.000507)$ & $(0.000487)$ & $(0.000479)$ \\
\hline & \multicolumn{5}{|c|}{$\%$ Absent Days } \\
\hline \multicolumn{6}{|l|}{ Hispanics - } \\
\hline \multirow[t]{2}{*}{ Late Entering First Gen. } & $-0.00488^{* * *}$ & $-0.00666^{* * *}$ & $-0.00616^{* * *}$ & $-0.0101^{* * *}$ & \\
\hline & $(0.000289)$ & $(0.000245)$ & $(0.000256)$ & $(0.000261)$ & \\
\hline \multirow[t]{2}{*}{ Early Entering First Gen. } & $-0.00950^{* * *}$ & $-0.00956^{* * *}$ & $-0.00907^{* * *}$ & $-0.0125^{* * *}$ & \\
\hline & $(0.000180)$ & $(0.000157)$ & $(0.000172)$ & $(0.000177)$ & \\
\hline \multirow[t]{2}{*}{ Second Generation } & $-0.00913^{* * *}$ & $-0.00927^{* * *}$ & $-0.00883^{* * *}$ & $-0.0125^{* * *}$ & $-0.0145^{* * *}$ \\
\hline & $(0.000175)$ & $(0.000136)$ & $(0.000146)$ & $(0.000150)$ & $(0.000159)$ \\
\hline \multirow[t]{2}{*}{ Third Generation } & $0.00390^{* * *}$ & $0.00409^{* * *}$ & $0.00432^{* * *}$ & $0.00168^{* * *}$ & $-0.000308^{* *}$ \\
\hline & $(0.000185)$ & $(0.000117)$ & $(0.000120)$ & $(0.000118)$ & $(0.000116)$ \\
\hline School-Year FE & No & Yes & Yes & Yes & Yes \\
\hline Native language & No & No & Yes & Yes & Yes \\
\hline FRPL eligible & No & No & No & Yes & Yes \\
\hline Maternal characteristics & No & No & No & No & Yes \\
\hline
\end{tabular}


Online Table 3 - Regression Adjusted Cross-Generational Differences in Hispanic High School Graduation, Compared to Third Generation White Students, Excluding Cuban and Puerto Rican Students

\begin{tabular}{|c|c|c|c|c|c|}
\hline & \multicolumn{5}{|c|}{ Graduated from High School } \\
\hline & $(1)$ & $(2)$ & $(3)$ & $(4)$ & $(5)$ \\
\hline \multirow[t]{2}{*}{ Late Entering First Gen. } & $-0.189^{* * *}$ & $-0.186^{* * *}$ & $-0.168^{* * *}$ & $-0.144^{* * *}$ & \\
\hline & $(0.00761)$ & $(0.00590)$ & $(0.00654)$ & $(0.00644)$ & \\
\hline \multirow[t]{2}{*}{ Early Entering First Gen. } & -0.000362 & $-0.00887^{*}$ & $0.00924^{*}$ & $0.0284^{* * *}$ & \\
\hline & $(0.00523)$ & $(0.00402)$ & $(0.00458)$ & $(0.00455)$ & \\
\hline \multirow[t]{2}{*}{ Second Generation } & 0.00285 & -0.00452 & $0.0111^{* *}$ & $0.0283^{* * *}$ & $0.0398^{* * *}$ \\
\hline & $(0.00595)$ & $(0.00387)$ & $(0.00420)$ & $(0.00416)$ & $(0.00437)$ \\
\hline \multirow[t]{3}{*}{ Third Generation } & $-0.0325^{* * *}$ & $-0.0354^{* * *}$ & $-0.0267^{* * *}$ & $-0.0133^{* * *}$ & 0.00478 \\
\hline & $(0.00562)$ & $(0.00390)$ & $(0.00403)$ & $(0.00388)$ & $(0.00382)$ \\
\hline & \multicolumn{5}{|c|}{ Took an Advanced Course Before High School Graduation } \\
\hline \multirow[t]{2}{*}{ Late Entering First Gen. } & $-0.103^{* * *}$ & $-0.157^{* * *}$ & $-0.115^{* * *}$ & $-0.0751^{* * *}$ & 0 \\
\hline & $(0.0139)$ & $(0.0104)$ & $(0.0107)$ & $(0.0104)$ & $()$. \\
\hline \multirow[t]{2}{*}{ Early Entering First Gen. } & $0.0352^{* *}$ & $-0.0234^{* *}$ & 0.0178 & $0.0514^{* * *}$ & 0 \\
\hline & $(0.0123)$ & $(0.00798)$ & $(0.00911)$ & $(0.00897)$ & (.) \\
\hline \multirow[t]{2}{*}{ Second Generation } & $-0.0339^{*}$ & $-0.0824^{* * *}$ & $-0.0457^{* * *}$ & -0.0126 & -0.00685 \\
\hline & $(0.0136)$ & $(0.00728)$ & $(0.00808)$ & $(0.00797)$ & $(0.00656)$ \\
\hline \multirow[t]{2}{*}{ Third Generation } & $-0.0389^{* *}$ & $-0.0927^{* * *}$ & $-0.0741^{* * *}$ & $-0.0550^{* * *}$ & $-0.0449^{* * *}$ \\
\hline & $(0.0119)$ & $(0.00651)$ & $(0.00663)$ & $(0.00653)$ & $(0.00633)$ \\
\hline High School x Cohort FE & No & Yes & Yes & Yes & Yes \\
\hline Native language & No & No & Yes & Yes & Yes \\
\hline FRPL eligible & No & No & No & Yes & Yes \\
\hline Maternal characteristics & No & No & No & No & Yes \\
\hline \multicolumn{6}{|c|}{$\begin{array}{l}\text { Notes: High school graduation regressions include } 10,758 \text { unique late entering first generation Hispanic students, } 14,108 \text { unique early entering first generation } \\
\text { Hispanic students, } 23,195 \text { unique second generation Hispanic students, } 15,685 \text { unique third generation Hispanic students, and } 154,758 \text { unique third generation } \\
\text { white students. Advanced course-taking regressions include } 5,217 \text { unique late entering first generation Hispanic students, } 7,374 \text { unique early entering first } \\
\text { generation Hispanic students, } 12,785 \text { unique second generation Hispanic students, } 8,178 \text { unique third generation Hispanic students, and } 92,346 \text { unique third } \\
\text { generation white students. Late (early) entering students are defined as the students who entered the Florida public school system after (before or during) the third } \\
\text { grade. Standard errors clustered at the school by year level in parentheses, }{ }^{*} p<0.05,{ }^{* *} p<0.01,{ }^{* * *} p<0.001 \text {. All models control for gender, age of the student } \\
\text { when he/she enters the ninth grade for the first time, special education status, and cohort fixed-effects. }\end{array}$} \\
\hline
\end{tabular}

